\title{
Mountain Waves over Mont Blanc: Influence of a Stagnant Boundary Layer
}

\author{
Ronald B. Smith and Steven Skubis* \\ Department of Geology and Geophysics, Yale University, New Haven, Connecticut \\ JAMES D. DOYLE \\ Naval Research Laboratory, Monterey, California \\ ADRIAN S. BROAD \\ Met Office, Bracknell, United Kingdom \\ Christoph Kiemle and Hans Volkert \\ Institute für Physik der Atmosphäre, DLR Oberpfaffenhofen, Oberpfaffenhofen, Germany
}

(Manuscript received 28 December 2000, in final form 4 September 2001)

ABSTRACT

\begin{abstract}
A stationary mountain wave, embedded in southwesterly flow over Mont Blanc in the Alps, was observed simultaneously by three research aircraft and three types of remote sensing: GPS dropsondes, airborne light detecting and ranging (lidar), and rapid-scan satellite imagery. These observations provide a basis for testing linear and nonlinear theories of how mountain waves over complex terrain are controlled by the ambient wind profile, especially the effects of a low-level stagnant layer and the jet stream aloft. The layer of blocked flow near the ground reduced the amplitude of the wave generation. The strong wind and weak stability in the upper troposphere forced the wave into a decaying "evanescent" state. In spite of this evanescent condition, no lee waves were observed. The authors resolve this paradox by demonstrating that the stagnant layer below $3 \mathrm{~km}$ played an additional role. It was able to absorb downward reflected waves, preventing the formation of a resonant cavity. Linear theory, including this low-level absorption, predicts the observed wave structure quite well and captures the wave absorption process found in the fully nonlinear Coupled Ocean-Atmosphere Mesoscale Prediction System (COAMPS) model. In spite of wave decay through the upper troposphere, there is evidence from satellite images and model simulation that the waves reached the uppermost troposphere.
\end{abstract}

\section{Introduction}

Since the first papers on mountain waves in the 1930s and 1940s, the emphasis has been on the effect of isolated ridges and peaks. Few theoretical papers and even fewer observational papers have dealt with the issue of complex terrain. The most complex situation that has received systematic study is a sequence of parallel ridges (Smith 1976; Welch et al. 2001). A central issue with complex terrain is the modification of the ambient flow by the full terrain and the influence of this modification on the waves produced by each topographic element.

\footnotetext{
* Current affiliation: Department of Earth Sciences, State University of New York at Oswego, Oswego, New York.
}

Corresponding author address: Dr. Ronald B. Smith, Dept. of Geology and Geophysics, Yale University, Kline Geology Lab, P.O. Box 208109, New Haven, CT 06520-8109.

E-mail: ronald.smith@yale.edu
While such complex situations can now be numerically simulated, verification requires an extraordinary effort to interpret complicated wave patterns, verify stationarity, and observe the flow below mountain top, where the ambient flow modification is most likely to occur.

A unique opportunity to attack this difficult problem arose in the Mesoscale Alpine Programme (MAP). The broad-scale features of the Alpine massif are known to cause blocking and flow splitting (Steinacker 1982; Chen and Smith 1987; Heimann 1997), which might modify the generation and propagation of smaller-scale gravity waves. During MAP, the dense existing observational network was enhanced with an unprecedented set of special observing systems, including four research aircraft, air-launched global positioning system (GPS) dropsondes, airborne light detecting and ranging laser (lidar), radar, an enhanced sounding network, and rapid scan satellite imagery (Bougeault et al. 2001).

In this paper, we evaluate the ability of new observing techniques, high-resolution numerical models and an ex- 


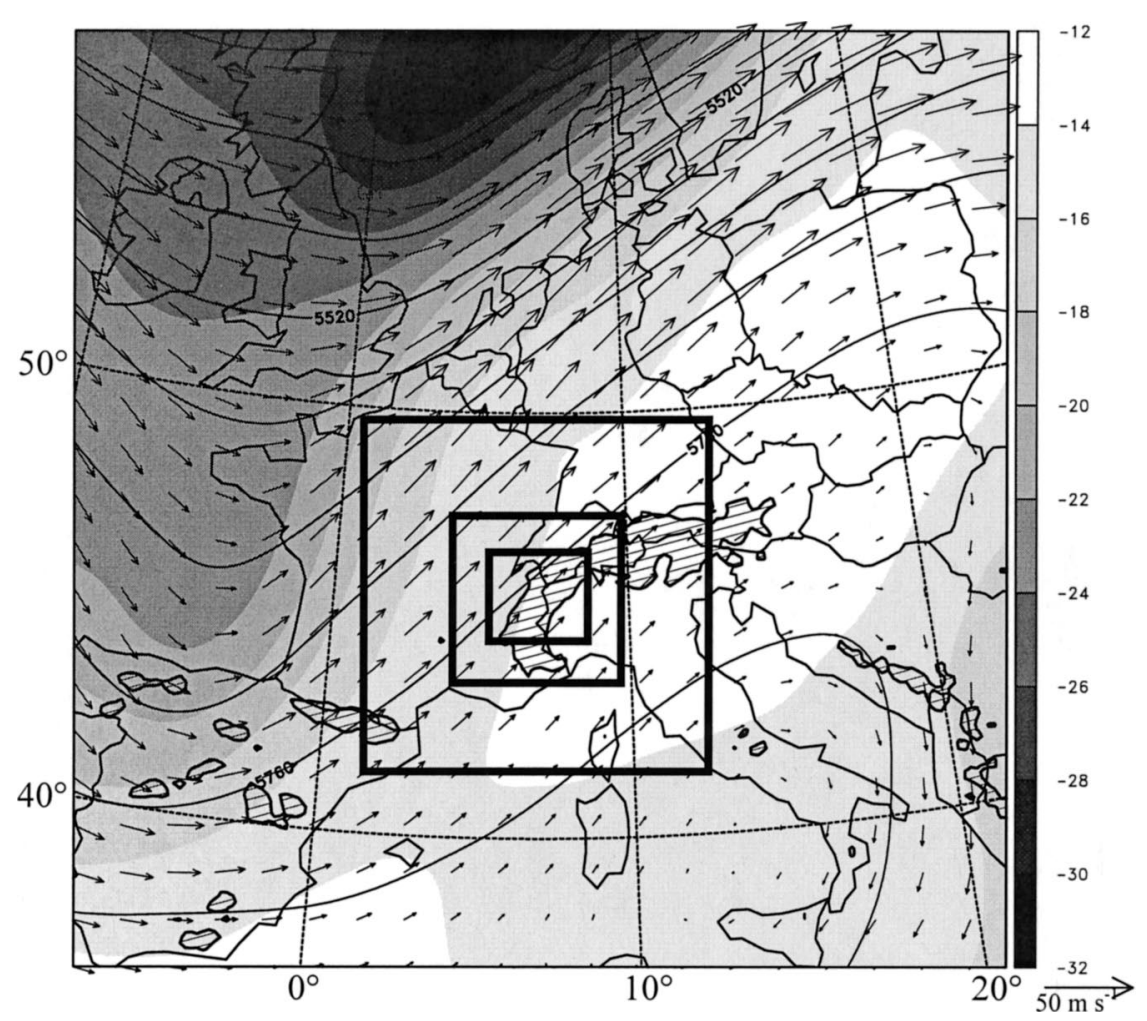

FIG. 1. Conditions over Europe on the 500-hPa surface at 0600 UTC on 2 Nov 1999. Geopotential height is contoured. Wind vectors are shown. Temperature is shaded. The inner three domains for the COAMPS runs are shown. A southwesterly wind of moderate strength was present over the western Alps.

tended linear wave model to clarify the dynamics of wave generation and propagation over complex terrain. In sections 2 to 6 , we present measurements taken during a wave event over Mont Blanc (MB) on 2 November 1999. In sections 7 to 9 , we interpret the measurements and discuss modeling of the event.

\section{The Mont Blanc case of 2 November 1999}

Near the end of the MAP Special Observing Period (7 September-15 November 1999), the aircraft used in this study were stationed in Innsbruck, Austria; Oberpfaffenhofen, Germany; and Milan, Italy, for deployment into predicted gravity wave events over the Alps. On 2 November 1999, a trough approaching the Alps from the west brought strong southwesterly flow against the high terrain of the northwestern Alps (Fig. 1). Aircraft were sent to observe mountain waves generated by the largest mountain in the region, Mont Blanc (4807 m; $\left.45.83^{\circ} \mathrm{N}, 6.68^{\circ} \mathrm{E}\right)$. Three aircraft performed repeated legs over the mountain. The National Center for Atmospheric Research (NCAR) Electra flew at altitudes of 5.5 and $6.4 \mathrm{~km}$, equipped with flight level instruments, down-looking scanning aerosol backscatter lidar (SABL), and GPS dropsondes. The UK C-130 flew at $7.6 \mathrm{~km}$ (8 repeated legs), equipped with flight level in- struments and GPS dropsondes. The DLR Falcon flew at 11.6 and $12.8 \mathrm{~km}$, equipped with flight level instruments, down-looking differential absorption lidar (DIAL), and GPS dropsondes.

Over a period of about $4 \mathrm{~h}$ in the late morning, these aircraft flew legs along a wind-oriented path across $\mathrm{MB}$, between end-points $45.7^{\circ} \mathrm{N}, 6.7^{\circ} \mathrm{E}$ and $46.69^{\circ} \mathrm{N}, 7.9^{\circ} \mathrm{E}$ (Fig. 2). The flight track strategy emphasized repeated legs to monitor temporal variation in the field, leaving the vertical structure to be determined by the other aircraft, the dropsondes and the lidars. Additional data are available from nearby conventional rawinsondes (e.g., Payerne, Lyon, Cuneo). Figure 2 shows the surrounding complex terrain, including Monte Rosa (MR, $4634 \mathrm{~m}$ ), $60 \mathrm{~km}$ east of $\mathrm{MB}$.

\section{The vertical profile of wind and temperature}

The GPS dropsondes from the three aircraft were combined with other data sources to give a single reference sounding (Fig. 3). Some discrepancies between these data sources limit the precision with which the profiles can be established. Above $12.5 \mathrm{~km}$, the Payerne soundings at 0600 and 1200 UTC were used. In the upper troposphere, the Payerne sounding was combined with flight level data and checked against dropsonde 


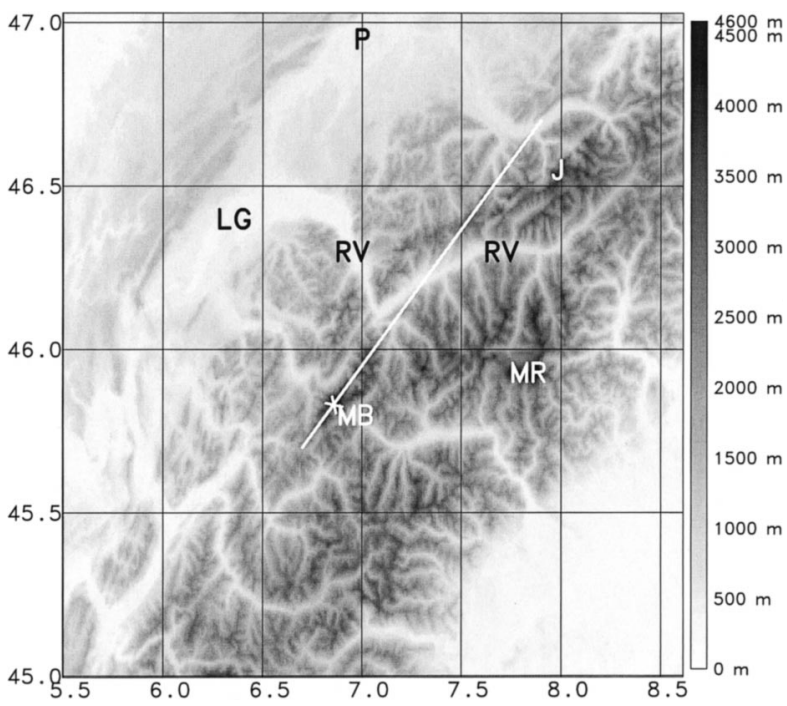

FIG. 2. The nominal flight track for the 2 Nov mission is shown superposed on the topography of the northwestern Alps. The location of Mont Blanc is shown with the symbol MB. The gridlines are latitude and longitude at half-degree increments. Lake Geneva (LG), upper Rhone Valley (RV), summits of Monte Rosa (MR), Jungfrau $(\mathrm{J})$, and the radiosonde station Payerne $(\mathrm{P})$ are labeled. The track passes over the MB massif and peak.

data from the C-130 and Falcon. Below $7.5 \mathrm{~km}$, dropsondes and flight level data from the Electra provided detailed wind and stability profiles. Below $5.5 \mathrm{~km}$, dropsondes encountered strong wind shear near $4 \mathrm{~km}$ and stagnant conditions below $2.5 \mathrm{~km}$, features not seen at Payerne. While some of these drops may have been influenced by mountain waves or wakes, their general agreement suggests that the stagnant layer encompassed a significant region around Mont Blanc.

According to linear lee-wave theory, the Scorer parameter controls the wave response to terrain forcing (Scorer 1949). For this analysis, we use the approximate form $\left[S^{2}(z)=N^{2}(z) / U^{2}(z)\right]$, as the shear vorticity term $\left(U_{\mathrm{zz}} / U\right)$ is difficult to estimate from real data. Also, as the shear term oscillates rapidly with height, its effect is probably small due to the averaging effect of the large vertical wavelength of the waves (see section 7). The significant decrease in $S$ near $7 \mathrm{~km}$ satisfied the Scorer condition for trapped lee waves. At $13 \mathrm{~km}$, the stability increased abruptly and above $13 \mathrm{~km}$, the wind speed decreased with altitude. The decreased wind speed and increased stability in the stratosphere increased the Scorer parameter there, possibly allowing lee-wave leakage and amplification of vertically propagating waves. For

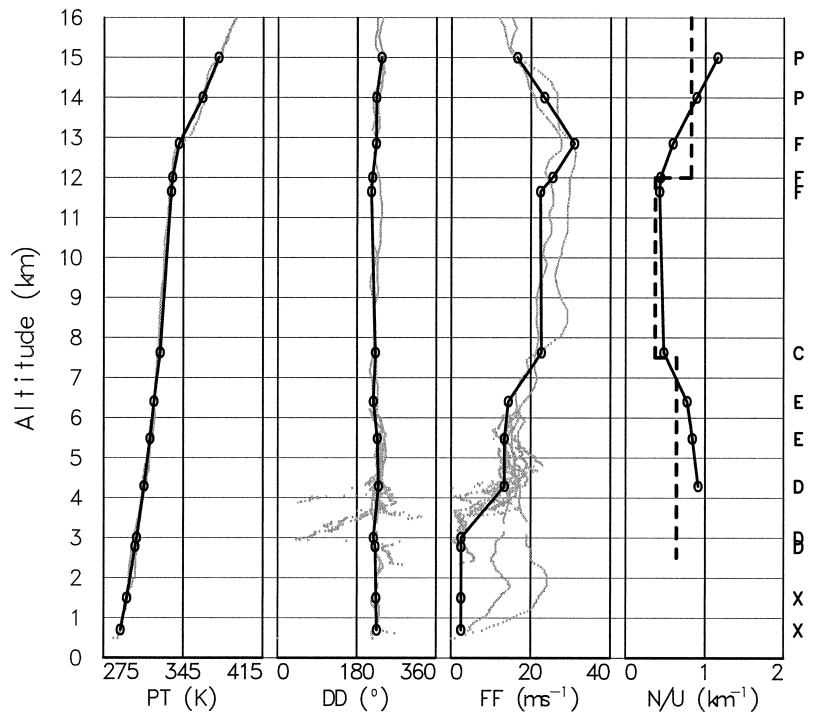

FIG. 3. Soundings for the 2 Nov case that represent the conditions during the flights. Data from three aircraft (F,C,E), 8 Electra dropsondes (D) between 1031:58 UTC and 1115:47 UTC, and the nearby Payerne (P) sounding (0600 and 1200 UTC) are combined to derive a reference sounding. Points (X) are extrapolated from the dropsondes and the Payerne temperature soundings. Variables shown are the potential temperature, wind direction and speed, and the simplified Scorer parameter $\left(N / U\right.$ with units in $\left.\mathrm{km}^{-1}\right)$. The idealized Scorer profile from Table 1 is shown dashed.

linear theory modeling, a three-layer idealization of the reference sounding was used. (Table 1, section 7).

\section{Aircraft data}

The aircraft and lidar data can be combined as in Figs. 4 and 5. In these figures, the vertical displacement of air parcels is computed from the aircraft-derived vertical velocity $w$ and mean horizontal velocity $U$ according to the steady-state linear formula

$$
\eta(x)=\int_{0}^{x}(w / U) d x
$$

The zero point of the integration is the upstream end of the flight leg. Falcon and Electra data at two levels, and C-130 data at one level, are shown. For the Electra, only the even-numbered legs are shown in Fig. 4, while the odd-numbered legs, flown with a slight lateral offset, are shown in Fig. 5. At the bottom of the figures, the terrain along the reference flight track is shown, taken from a 1-km global dataset (Gtopo30).

TABLE 1. Idealized three-layer reference atmosphere used in linear theory.

\begin{tabular}{cccccc}
\hline \hline Layer & $\begin{array}{c}\text { Wind speed } \\
(\mathrm{FF}) U\left(\mathrm{~m} \mathrm{~s}^{-1}\right)\end{array}$ & $\begin{array}{c}\text { Wind direction } \\
(\mathrm{DD})\end{array}$ & $\begin{array}{c}\text { Buoyancy frequency } \\
N\left(\mathrm{~s}^{-1}\right)\end{array}$ & $\begin{array}{c}\text { Scorer parameter } \\
S=N / U\left(\mathrm{~m}^{-1}\right)\end{array}$ & $\begin{array}{c}\text { Altitude range } \\
(\mathrm{km})\end{array}$ \\
\hline 1 & 15 & 220 & 0.012 & 0.0008 & $2.5-7$ \\
2 & 21 & 220 & 0.009 & 0.00043 & $7-12$ \\
3 & 31 & 220 & 0.02 & 0.00061 & Above 12 \\
\hline
\end{tabular}




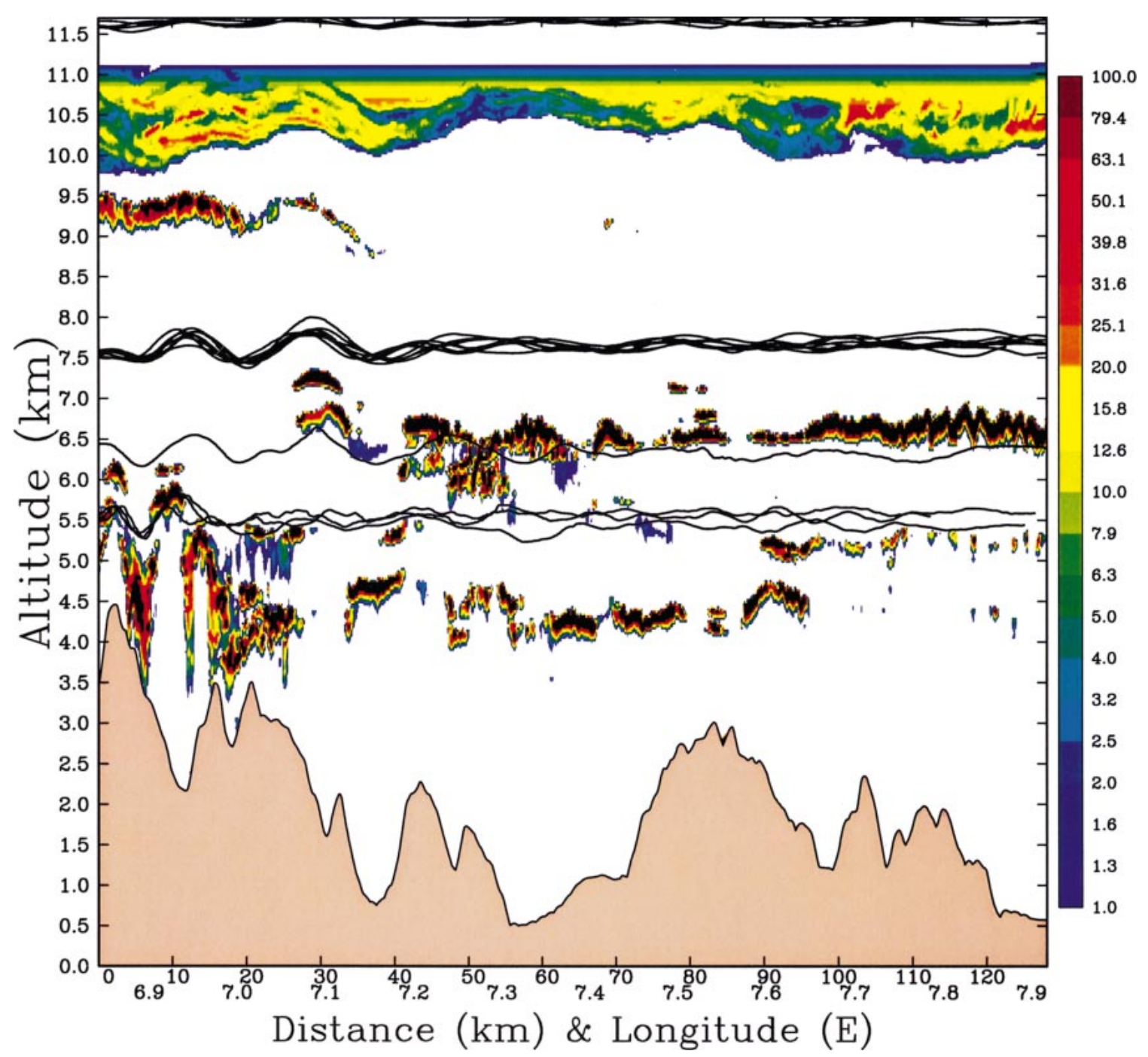

FIG. 4. The vertical section of DIAL backscatter coefficient from the first Falcon traverse over Mont Blanc. Also shown are the vertical parcel displacements, computed from Eq. (1), using data from the three research aircraft: Electra, C-130, and Falcon. Only the even-numbered legs of the Electra are shown.

A striking aspect of the aircraft-derived displacement data is the repeatability of the different legs, especially for the $\mathrm{C}-130$. This repeatability indicates that the wave field is nearly steady over the 4-h period of observations. Only two displacement minima and maxima are seen, indicating that wave dispersion is small and that trapped lee waves are not present. At an altitude of $7.6 \mathrm{~km}$, the distance between the two crests is about $17 \mathrm{~km}$, corresponding to a downstream horizontal wavenumber of $k=0.00037 \mathrm{~m}^{-1}$, slightly smaller than the Scorer parameter in layer 2 (Table 1 ). The peak-to-trough amplitude of the displacement is about $0.8,0.5,0.5$, and $0.2 \mathrm{~km}$ at altitudes of $5.5,6.4,7.6$, and $11.6 \mathrm{~km}$, respectively. At $11.6 \mathrm{~km}$, only one crest is observed. The Electra-derived displacement fields at $5.5 \mathrm{~km}$ differ from the odd and even legs (Figs. 4 and 5) due to the offset in the flight track. As we will see, the Mont Blanc wave field is highly three-dimensional.

In spite of wave tilt and dispersion, the location of the two displacement crests suggests that we can associate the first crest with the peak of Mont Blanc. The second crest seems to arise from the leeside slope of the MB massif, although it may be enhanced by dispersion of the waves from the first peak. The second crest is smaller than the first in the lower troposphere, but dominates aloft. This increasing dominance of the second crest may be due to the broader width of the massif lee slope, reducing the rate of three-dimensional dispersion aloft.

The highest legs of the Falcon provide evidence of waves in the cirrus cloud. As the aircraft ascended from 11.7 to $12.4 \mathrm{~km}$ at $1100 \mathrm{UTC}$, the ozone concentration 


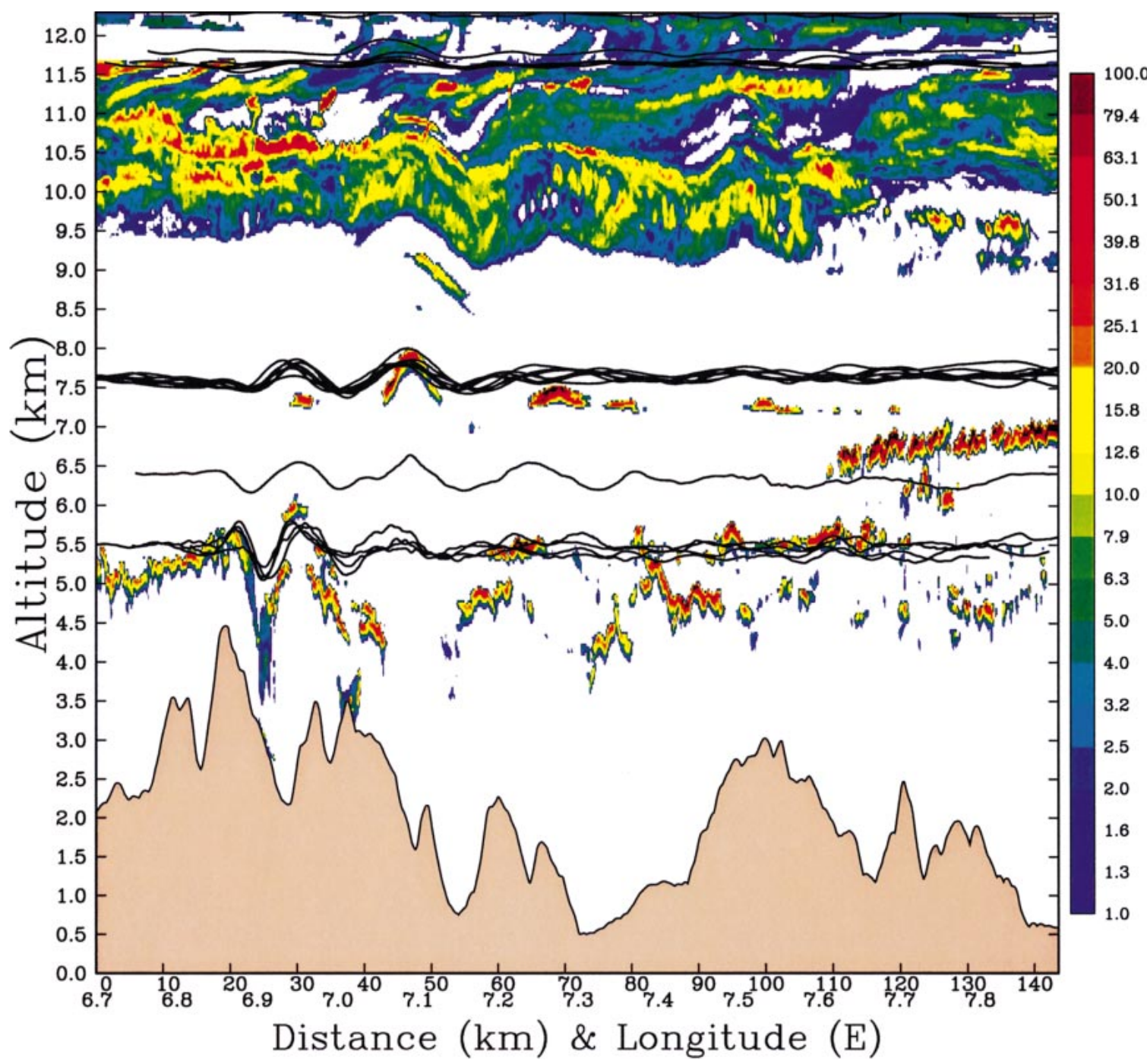

FIG. 5. Similar to Fig. 4, but for the last of the six Falcon legs. Only the odd-numbered Electra legs are shown.

increased from 30 to $45 \mathrm{ppbv}$, while the temperature decreased to $-65^{\circ} \mathrm{C}$. This increase in ozone may indicate a proximity to the tropopause, but $45 \mathrm{ppbv}$ is still usually considered to be a tropospheric concentration. The negative lapse rate supports this interpretation. The frostpoint remained equal to the temperature, even at the highest aircraft level, indicating that the water vapor was saturated with respect to ice, consistent with the lidar and visual observation that the Falcon was still in the cirrus layer. The single weak wave at an altitude of $12.4 \mathrm{~km}$ lies directly above the single wave at 11.7 $\mathrm{km}$, but is even weaker. Its structure is somewhat contaminated by a possible phugoid oscillation of the aircraft in the presence of strong reverse vertical shear. The horizontal wind speed shows systematic slowing over Mont Blanc-perhaps an indication of gravity waves.

\section{Lidar data}

A good representation of the wave field is also seen in the data from the new DLR DIAL system mounted on the Falcon [see Ehret et al. (2000) and our appendix $\mathrm{B}]$, due to the fortunate occurrence of clouds at several levels (Figs. 4 and 5). A surprising aspect of this data is that the lidar could penetrate the deep cirrus layer to give additional information about mid- and lower-layer cloud structures. These denser clouds below, however, attenuated the beam, preventing still lower clouds from being sensed. In a few spots, the beam reached the surface of the earth. Altitudes retrieved for these locations agreed with the terrain data (Gtopo30) using the aircraft GPS position. The lidar backscatter intensity is proportional to the number and size of the cloud particles present in each resolved volume. The DIAL section for the first and last traverses are quite similar. 
The lowest cloud layer was seen at $z=5.5 \mathrm{~km}$. This layer rose slightly and then plunged downward by 1500 $\mathrm{m}$ just downstream of the Mont Blanc peak. The fact that the cloud layer did not disappear until it dropped to an altitude of $4 \mathrm{~km}$ indicates that it had a significant amount of condensed water to begin with. The location of the plunge agreed with the Electra-derived downward parcel displacement (1), but was three times as large. The Electra apparently skimmed just over the MB "waterfall." The plunging cloud layer was nearly identical in each of the six subsequent DIAL images, as well as in the numerous Electra SABL images (not shown). The dynamical feature and the cloud layer that made it visible must have been approximately in steady state.

In the middle troposphere, a striking lenticular cloud was observed at $z=7.5$ and $d=47 \mathrm{~km}$ in Fig. 5. Of the six DIAL cross sections, only the one shown in Fig. 5 had this particular cloud feature. The study of all six sections suggests that packets of moisture were drifting through the region at this level, allowing only brief glimpses of wave cloud activity. The location of the cloud agreed well with the C-130-derived parcel displacement. A good photograph of the lenticular cloud was taken from the C-130 (Fig. 6).

In Fig. 4, a thin cloud layer was seen at an altitude of $9 \mathrm{~km}$. It oscillates vertically, in phase and with a similar amplitude to the aircraft-derived parcel displacements. The density of the cloud layer did not appear to increase significantly as the air is lifted. The study of all six DIAL images showed that this layer of moisture moved downwind during the observing period. In the last traverse (Fig. 5) only the trailing edge of the moisture layer was seen, expressed as a half-lenticular cloud at $d=50 \mathrm{~km}$.

In the upper troposphere, a deep cirrus layer was seen from 9.5 to at least $12.5 \mathrm{~km}$. The base of this layer and two denser layers within it were displaced vertically in concert with the wave field. This general pattern was nearly constant from scan to scan. The fact that the wave was displacing but not creating and destroying the cloud layers indicates that there are strong vertical gradients in relative humidity. Vertical displacements are smaller at the top of the image, possibly because of wave attenuation or the stronger wind speed there. We interpret the sloping backscatter patterns near the top of the cirrus layer as fall streaks. Most of the fall streaks in the figure are distorted by the gravity wave field.

The photograph taken from the C-130 (Fig. 6) shows the other types of clouds seen by the DIAL as well. The high cirrus appears as a continuous overcast layer at the top of the photo. The ragged cumulus clouds at $5.5 \mathrm{~km}$ are also seen. Some of the Alpine terrain is evident in the lower part of the photograph.

The combined images of cloud distribution and aircraft-derived vertical displacement (Figs. 4 and 5) illustrate two types of relationship between wave displacement and clouds. Two well-defined cloud layers, the cirrus layer $(9.5-12.5 \mathrm{~km})$ and the cumulus layer $(5.5 \mathrm{~km})$, are displaced up and down by the waves, with little change in cloud density. The two other moist layers ( 7.5 and $9 \mathrm{~km}$ ) form "wave clouds" when moist air is lifted by the waves.

An important feature of Figs. 4 and 5 is the behavior of wave amplitude and phase with altitude. Some upstream phase shift is seen between $z=5.5$ and $6.4 \mathrm{~km}$, but little additional phase shift is present aloft. The amplitude decreases aloft, in agreement with the aircraft observations. We will investigate these issues in sections 7 and 8 .

\section{Rapid-scan Meteosat images}

An additional dataset available in MAP was rapidscan Meteosat-6 imagery. These images are rather coarse for our application (3-km pixels), but the short time interval between images ( $5 \mathrm{~min}$ ) allows one to see fast-moving cloud features. The visible images showing the cirrus deck are most useful for our purpose. The IR images show a similar pattern but with inferior resolution. Even in the visible image, however, the pattern is so irregular that the individual images are difficult to interpret. No clear wave pattern was seen.

We began our analysis of Meteosat data by making a 3-h film loop of the visible images. In this loop, randomly distributed bright and dark patches on the cirrus deck over the eastern Alps are seen drifting from southwest to northeast, a direction that agrees with our other estimates of the mean wind vector. Superimposed on this general drift are a few stationary bright and dark features located over and downstream of Mont Blanc and Monte Rosa. We interpret these features as stationary mountain wave crests and troughs, modulating the cloud density. In addition, some very dark patches are observed to form over Mont Blanc and drift downstream. These are the darkest patches in the scene.

To analyze these stationary and moving patterns, we have constructed a time-distance Hovmöller diagram of relative reflectivity along a wind-oriented line parallel to the MB flight tracks (Fig. 7). The most striking features are seen along a line offset southeastward from the flight track by two pixels. The temporal change in reflected radiance due to the rising sun was removed by dividing the brightness value for each pixel by the average scene brightness, before constructing the timedistance section. The range of brightness was then enhanced for improved contrast. In this diagram, drifting cloud elements appear as rightward slanting features. The slope of the feature determines its speed. In Fig. 7, the typical drift speed of cloud features is about $13 \mathrm{~m}$ $\mathrm{s}^{-1}$. With reference to the wind profile in Fig. 3, we estimate the altitude of the cloud top to be about $15 \mathrm{~km}$.

We are particularly interested in bright and dark features that appear "vertical" (i.e., parallel to the time axis). Such features occur primarily in proximity to the MB terrain. A stationary bright patch is seen between $x=80$ and $100 \mathrm{~km}$, almost directly over Mont Blanc. This is followed by a trough at $x=100 \mathrm{~km}$, a crest at $x=107 \mathrm{~km}$, and a trough at $x=118 \mathrm{~km}$. Fainter crests 


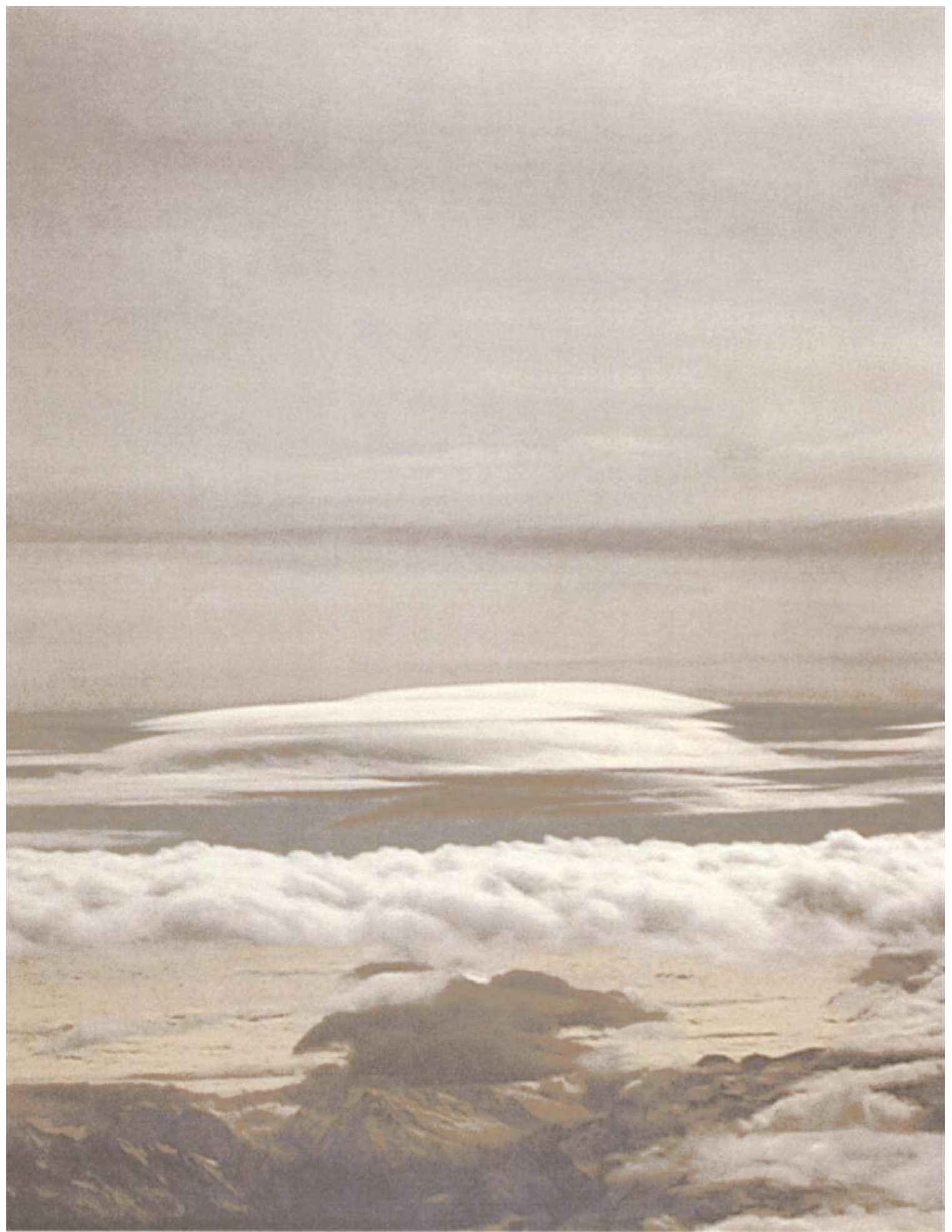

FIG. 6. Photograph taken from the cockpit of the $\mathrm{C}-130$ showing cloud types present during the mission: cirrostratus aloft, lenticularis at flight-level, and cumulus below. 


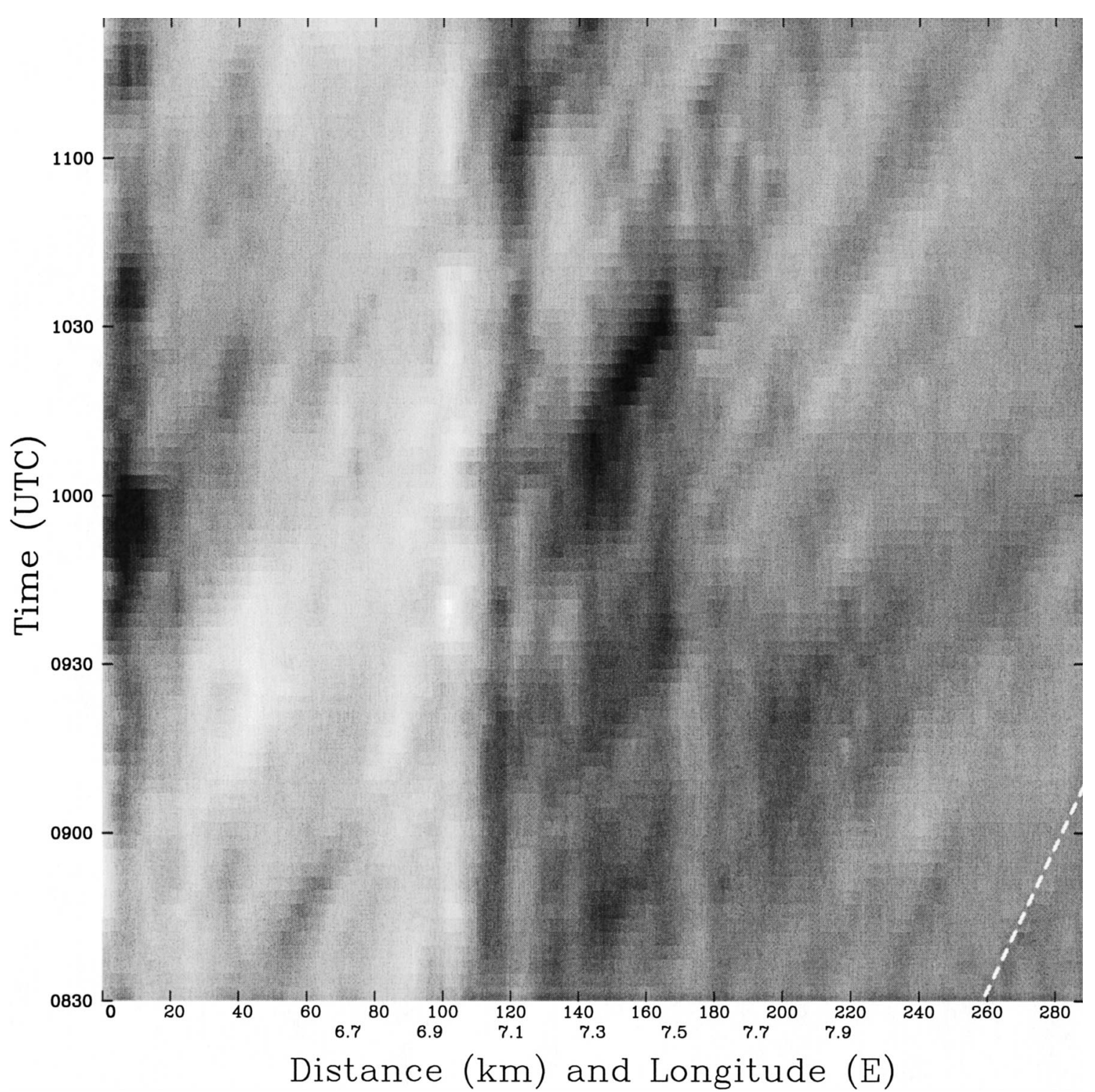

FIG. 7. Meteosat rapid-scan data (2 Nov 1999). A time-distance (i.e., Hovmöller) diagram of reflected radiance along a southwest-northeast line located $6 \mathrm{~km}$ east of the flight track is shown. Stationary waves appear as vertical bright and dark bands in this diagram. Downwind drifting disturbances slant toward the upper right. The slope of these traces indicates a drift speed of $13 \mathrm{~m} \mathrm{~s}^{-1}$ (see reference slope, dashed). Dark features appear to form in the first wave trough and drift downstream.

are seen at $x=125$ and $140 \mathrm{~km}$. The average wavelength of the stationary features is about $15 \mathrm{~km}$.

\section{Linear theory}

Due to the relatively small amplitude and steady nature of the observed wave, it is appropriate to choose steady-state linear theory to begin the interpretation of the event. Nonlinear aspects are also examined in section 9 using the navy's Coupled Ocean-Atmosphere Mesoscale Prediction System (COAMPS) model. The current three-layer 3D formulation of linear theory extends the work of Sawyer (1962), using the fast Fourier trans- form (FFT) method of Smith (1980). Related models have been used more recently by Simard and Peltier (1982), Sharman and Wurtele (1983), Thorpe at al. (1993), and Vosper and Mobbs (1996). The equations of linear mountain wave theory, with the Boussinesq approximation, are

$$
\begin{aligned}
U u_{x}+V u_{y}+U_{z} w & =-\left(1 / \rho_{0}\right) p_{x}^{\prime}, \\
U v_{x}+V v_{y}+V_{z} w & =-\left(1 / \rho_{0}\right) p_{y}^{\prime}, \\
U w_{x}+V w_{y} & =-\left(1 / \rho_{0}\right) p_{z}^{\prime}-\left(\mathrm{g} / \rho_{0}\right) \rho^{\prime}, \\
u_{x}+v_{y}+w_{z} & =0, \\
U \rho_{x}^{\prime}+V \rho_{y}^{\prime}+(d \rho / d z) w & =0,
\end{aligned}
$$


where $u(x, y, z), v(x, y, z), w(x, y, z), p^{\prime}(x, y, z)$, and $\rho^{\prime}(x, y, z)$ are the perturbation velocity components, pressure, and density; $U(z), V(z)$, and $\rho(z)$ are the environmental wind and density profiles. The symbols $g$ and $\rho_{0}$ are the acceleration of gravity and a reference density. Subscripts indicate partial derivatives. Equations $(2 \mathrm{a}),(2 \mathrm{~b})$, and $(2 \mathrm{c})$ are the three momentum equations, while (2d) and (2e) are the continuity and density conservation equations. Combining (1) and (2), and performing a Fourier transform from $(x, y)$ to $(k, l)$ coordinates, we obtain a single equation for vertical displacement $\hat{\eta}(k, l, z)$ :

$$
\left(\sigma^{2} \hat{\eta}_{z}\right)_{z}+\left(k^{2}+l^{2}\right)\left(N^{2}-\sigma^{2}\right) \hat{\eta}=0,
$$

where the intrinsic frequency $\sigma=U k+V l$. Within each layer of constant wind and stability $(i=1,2,3), \sigma_{z}=$ 0 , and $N$ and $\sigma$ are constant, so the solution to (3) is

$$
\hat{\eta}_{i}(k, l, z)=A_{i} \exp \left(i m_{i} z\right)+B_{i} \exp \left(-i m_{i} z\right),
$$

where the vertical wavenumber is given by $m_{i}^{2}=\left(k^{2}\right.$ $\left.+l^{2}\right)\left(N_{i}^{2}-\sigma_{i}^{2}\right) / \sigma_{i}^{2}$, and $A_{i}$ and $B_{i}$ are the amplitude coefficients for the up- and down-going waves, respectively. A consistent sign for $m$ is given by $\operatorname{sgn}(\sigma)$. When the magnitude of the intrinsic frequency is much smaller than the buoyancy frequency (i.e., $|\sigma| \ll N$ ), the vertical wavenumber is nearly independent of $\sigma$, exactly so if the wind is parallel to the wavenumber vector. We say that the wave is nondispersive. When $\sigma$ is close to $N$, the wave is dispersive due to nonhydrostatic effects. When the intrinsic frequency is greater than the buoyancy frequency (i.e., $|\sigma|>N$ ), the vertical wavenumber $m$ is imaginary and the solutions are exponential rather than trigonometric. In this case, nonhydrostatic effects are dominant and we describe the wave as evanescent. Across the interfaces between the layers, continuity of mass and pressure require the jump conditions

$$
\begin{aligned}
\Delta \hat{\eta} & =0 \quad \text { and } \\
\Delta \sigma^{2} \hat{\eta}_{x} & =0 .
\end{aligned}
$$

If the value of intrinsic frequency for a particular wave component changes sign or drops to zero across an interface due to wind turning or reversal (Broad 1995; Shutts and Gadian 1999), (5) and (6) are replaced with an absorption condition. This option is not used in the present study as the observed wind direction is uniform with altitude. The radiation condition aloft is applied in the top layer (i.e., $B_{3}=0$ ). The linearized lower boundary condition is

$$
\eta(x, y, 0)=h(x, y)
$$

which, in Fourier space, is written

$$
A_{1}+B_{1}=\hat{h}(k, l) \text {. }
$$

The base level in our calculation is taken to be the reference height $\left(Z_{\text {ref }}\right)$. To calculate the effective topography $h(x, y)$ we began with the actual Alpine terrain from the 1-km-resolution global dataset available from the U.S.

\section{Jet Stream}

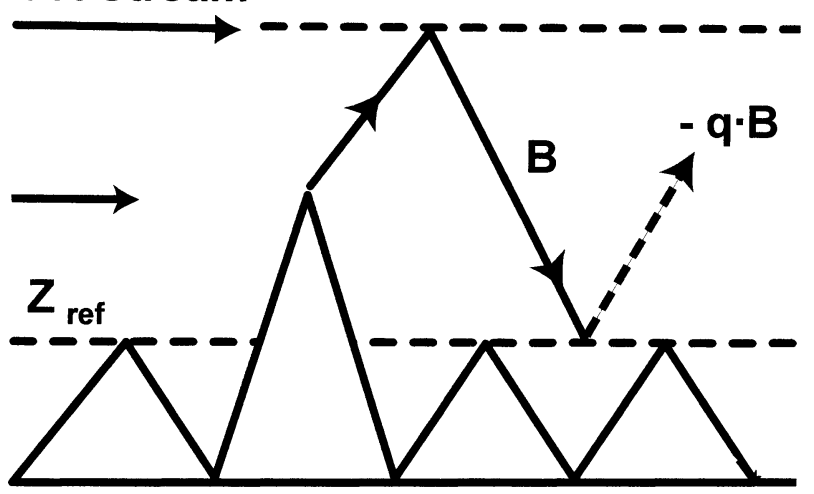

FIG. 8. Schematic of the resonant cavity for lee waves. The triangles represent the lower mountains, with one higher peak (i.e., Mont Blanc) penetrating into the ambient flow. The dashed line labeled $Z_{\text {ref }}$, is the top of the stagnant layer and the bottom of the linear theory domain. The upper dashed line represents the level of wave reflection due to decreasing Scorer parameter. The slanting wave rays are parallel to the local group velocity. The down-going wave amplitude $B$ is reduced by partial absorption at $Z_{\text {ref }}$, characterized by the reflection coefficient $q$.

Geological Survey (Gtopo30). Terrain height values were thresholded so that only terrain that penetrates above $Z_{\text {ref }}$ enters the calculation. That is, the effective terrain is given by positive values of $h(x, y)-Z_{\text {ref }}$. Furthermore, the terrain is reduced at the edge of the domain to eliminate spurious wrapping associated with the FFT method. This reduction uses a Gaussian factor, centered on Mont Blanc, with an $e$-folding scale of $100 \mathrm{~km}$.

To represent wave absorption at the lower boundary, we introduce a reflection coefficient $q$ so that (8) is modified to become

$$
A_{1}=\hat{h}(k, l)-q B_{1} .
$$

In this form, the up-going wave amplitude $\left(A_{1}\right)$ is seen to be the sum of the wave generated by the terrain $h$ and the reflected and phase-reversed down-going wave $B_{1}$ (see Fig. 8). If dissipation of the down-going wave occurs by boundary layer turbulence or critical layer absorption at the lower boundary, this effect can be parameterized by setting $q<1$. When $q<1$, condition (7) is no longer precisely satisfied. Away from the rigid mountain surface, the vertical parcel displacements at $z$ $=Z_{\text {ref }}$ represent fluctuations at the top of the boundary layer associated with the absorption mechanism. The slight distortion of the mountain surface can be eliminated by an iterative correction, but in practice this is not needed. The small magnitude of the mountain shape distortion introduced by (9) can probably be attributed to the fact that waves that are reflected by layer 2 , are already dispersive in layer 1 , and thus have a downstream component to their group velocities. They return to $Z_{\text {ref }}$ well downstream of the hill.

The current formulation of linear theory, for a specified atmospheric structure (i.e., Table 1), contains two free parameters: $Z_{\text {ref }}$ and $q$. The choice of base level for 


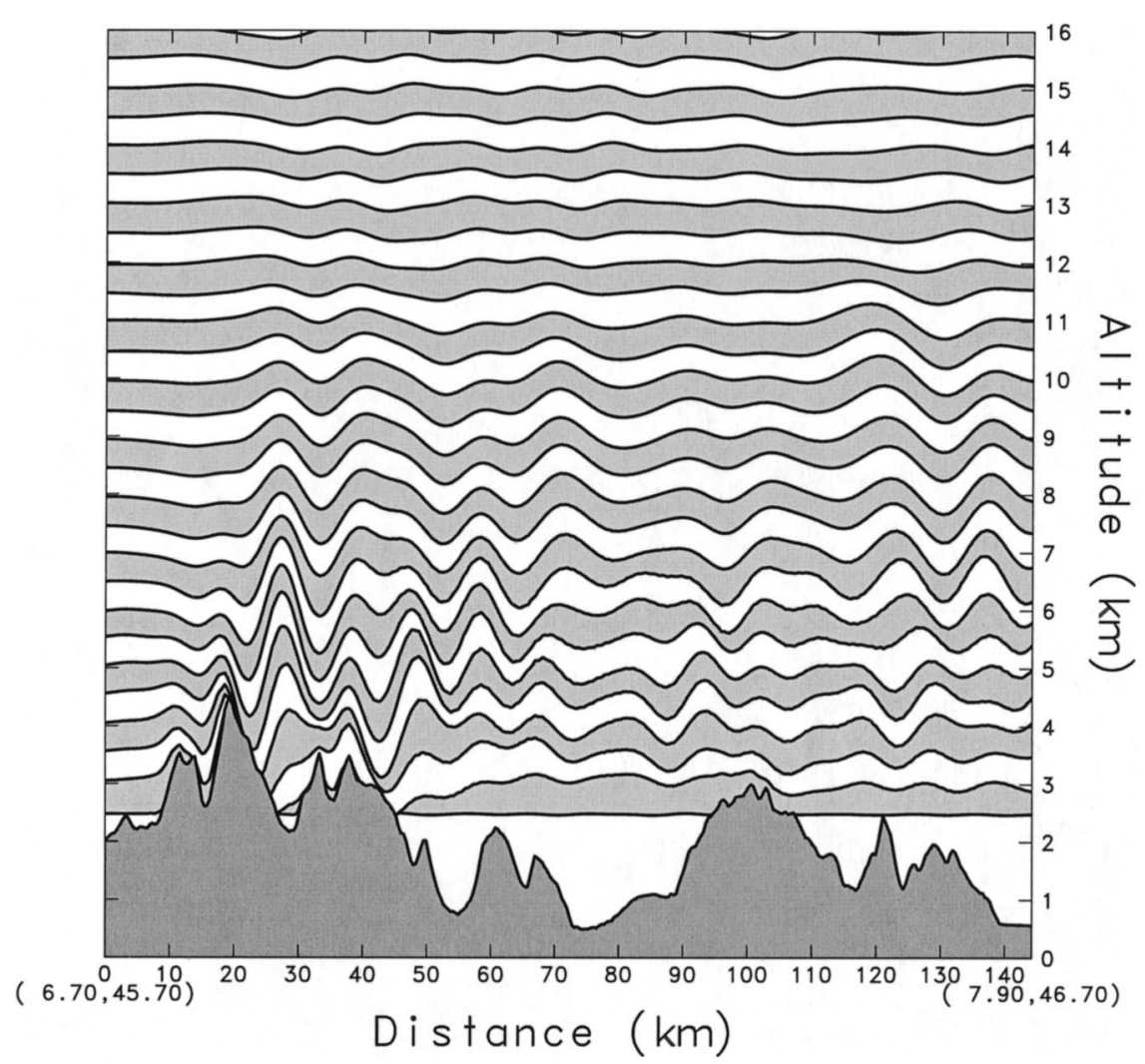

FIG. 9. A vertical section showing the field of vertical displacement predicted from a threelayer three-dimensional linear theory [Eqs. (2)-(9)] with the reflection coefficient $q=0.9$. The base level for the calculation is $2.5 \mathrm{~km}$. The vertical profile of wind and stability used in the calculation is given in Table 1. Note the presence of trapped lee waves downstream.

the calculation $\left(Z_{\text {ref }}\right)$ is made to represent the stagnant layer below $2500 \mathrm{~m}$, as found by the dropwindsondes. The choice of $Z_{\text {ref }}=2500 \mathrm{~m}$ is at the low end of possible values. Values as high as $3200 \mathrm{~m}$ could be defended (see Fig. 3). The reflection coefficient $q$ is varied to examine the nature of the lower boundary. When $q=$ 0 , all down-going waves are absorbed, consistent with the idea that a critical level is present at the top of the stagnant layer. When $q=1$, waves are reflected, allowing trapped lee waves to form if the Scorer condition is met aloft. In practice, we use $q=0.9$ instead of $q$ $=1$ to represent reflective conditions. This choice produces a slow decay of lee waves downstream that prevents periodic wrapping of the wave field in the finite domain due to the Fourier solution method. In the region of interest, the difference between $q=1$ and $q=0.9$ is minor. The hypothesis that a low-level stagnant layer can be modeled with an elevated $Z_{\text {ref }}$ and a zero reflection coefficient $(q=0)$ is tested in section $9 \mathrm{~b}$.

To display the linear theory fields, the parcel displacement are computed from

$\eta(x, y, z)=\exp (z / 2 H) \iint \hat{\eta}(k, l, z) \exp (i k x+i l y) d k d l$ at several altitudes using an inverse FFT, thus generating a full 3D field. We use a 1-km grid with 1024 by 1024 array that includes a considerable buffer zone around the region of interest. The computation runs in a few minutes on a workstation. The displacement field can be shown in vertical section or in planform view, or values can be extracted along a flight track for comparison with aircraft data. The growth of wave amplitude with height due to non-Boussinesq effects is captured by the factor $\exp (z / 2 H)$, where $H$ is the densityscale height. Equations for the coefficients $A_{i}$ and $B_{i}$ are given in appendix A. Further discussion of the threelayer model is given in Smith (2001).

\section{Comparison of linear theory and observations}

To determine the degree of model complexity needed to fit the data, four versions of linear theory calculations were compared with the observations. These models are 1) hydrostatic with uniform wind and stability, 2) nonhydrostatic with uniform wind and stability, 3) nonhydrostatic with the real wind profile and with $q=0.9$, and 4) nonhydrostatic with the real wind profile and with $q=0$. Of these trials, model 4 gives the best agreement, as described below. The results from models 3 and 4 are 


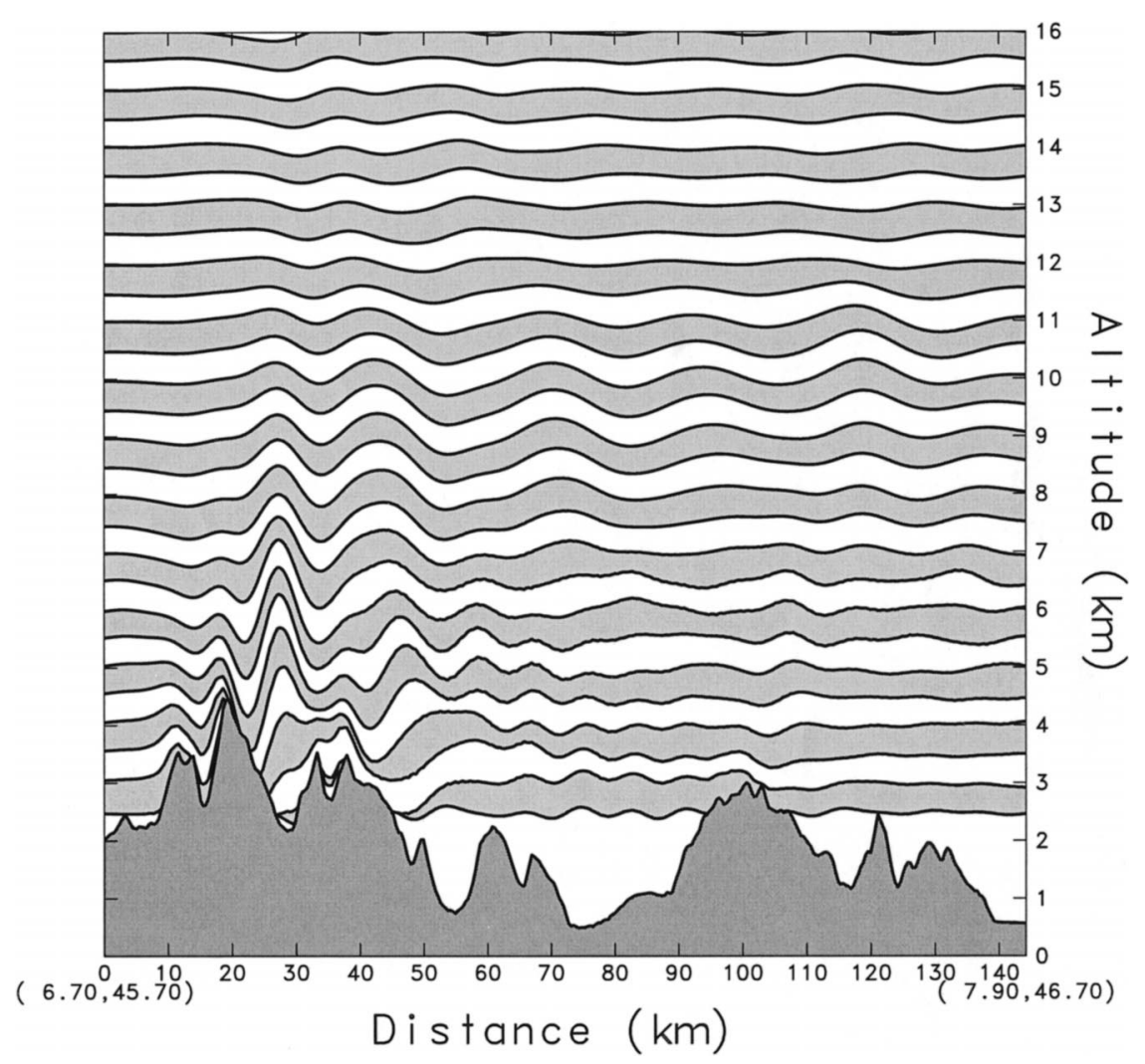

FIG. 10. Similar to Fig. 9, but with the reflection coefficient $q=0.0$. Careful comparison with Fig. 9, shows that trapped waves are absent. Note disturbance on the lowest streamline.

shown in Figs. 9 and 10. The results from models 1 and 2 are not shown in figures, but are discussed below.

In model 1, we force the waves to be hydrostatic by dropping $\sigma$ compared to $N$ in (3). Furthermore, the low troposphere values for stability and wind speed $\left(N_{1}\right.$ and $U_{1}$ ) are used at all levels. By forcing the model to be hydrostatic, waves of all scales are allowed to propagate vertically. This approach gives complex wave fields at all altitudes with phase tilt and growing amplitude, due to the density effect. The agreement with the Electra data is fair, if the field is smoothed, but the agreement with aircraft data from higher altitudes is poor.

Model 2 is nonhydrostatic with uniform wind $\left(U_{1}\right)$ and stability $\left(N_{1}\right)$. It is an improvement over model 1 as the small-scale structures (i.e., those with $\sigma>N_{1}$ ) are evanescent and decay rapidly aloft. This decay is realistic, as the Electra flight level data give no indication of waves generated by the small-scale topography. The use of the layer 1 Scorer parameter at all levels, however, allows the longer waves to propagate aloft as in model 1, and the same discrepancy with data further aloft is found. The waves are too large in the upper troposphere and show a strong phase tilt.

Model 3 is nonhydrostatic with the wind and stability profile given in Table 1 and with $q=0.9$ (Fig. 9). The two observed crests over Mont Blanc are seen, along with a complex array of quasi-periodic waves. In this model, the dominant wavelength of about $14 \mathrm{~km}$ becomes evanescent, or nearly so, in layer 2. Its downstream wavenumber component $k=0.00044 \mathrm{~m}^{-1}$ is slightly greater than $N_{2} / U_{2}$ (Table 1$)$. In the evanescent layer, there is no phase tilt and the amplitude decays markedly, overpowering the effect of decreasing density. This decay and lack of tilt agrees with the aircraft and lidar observations.

As expected, well-developed lee waves are also seen in this run. According to mountain wave theory, the evanescent behavior in the jet stream inevitably reflects some wave energy downward. These waves, after reflecting from the lower boundary, form a train of trapped lee waves. Such a lee-wave train was not observed, however. This inconsistency leads to the primary paradox of this study. We have strong observational evidence for evanescent behavior aloft, but yet no evidence for trapped lee waves.

Model 4 is similar to model 3, but with $q=0$ (Fig. 10). As in model 3, the dominant wave propagates though layer 1 and becomes evanescent in layer 2 . With $q=0$, however, the downward reflected wave is absorbed at the lower boundary and no lee waves are seen. This result agrees with observations. The two observed crests over Mont Blanc are still present, verifying that they are vertically propagating waves rather than 


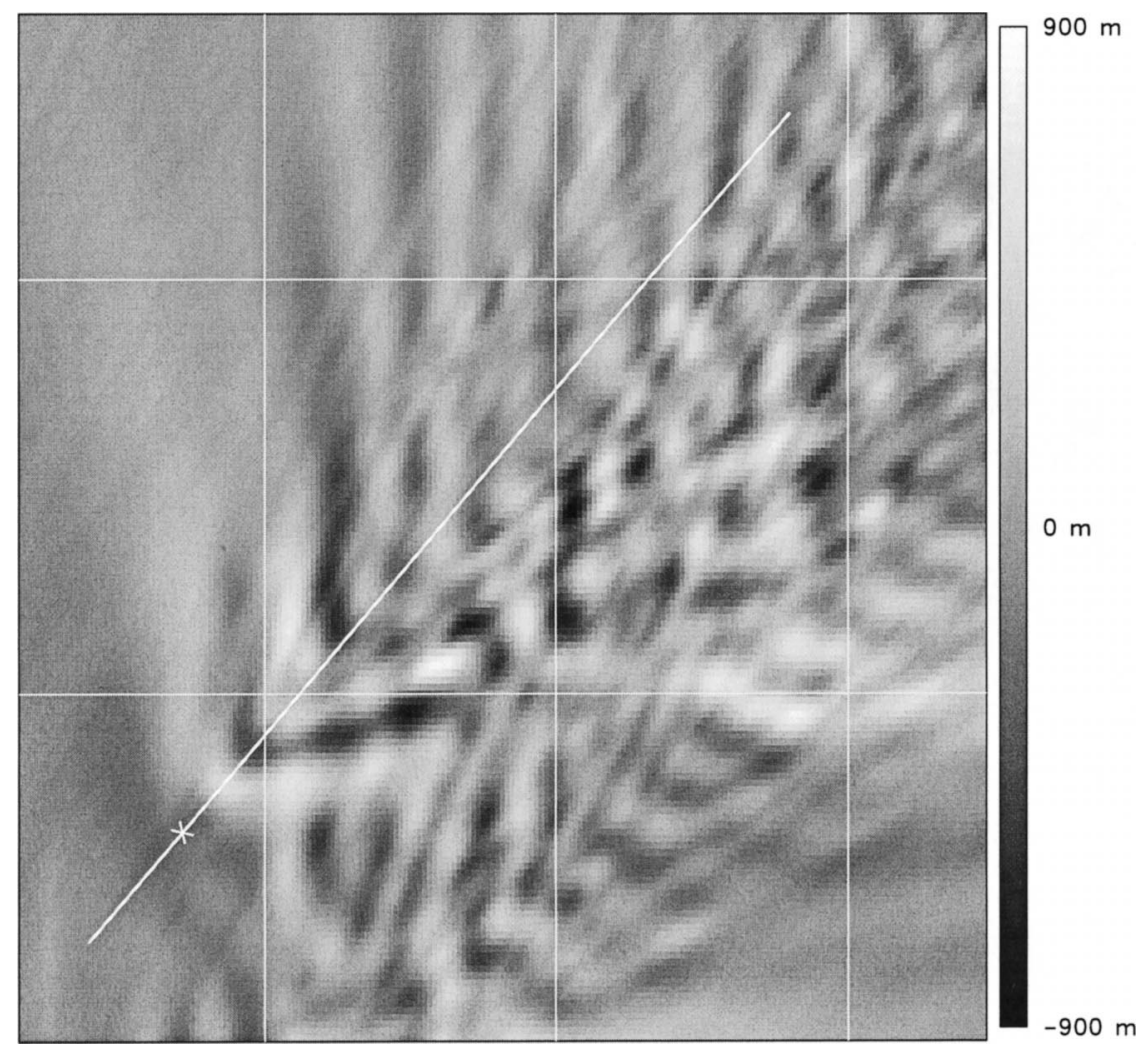

FIG. 11. Planview of the linear theory vertical displacement field at $z=7.5 \mathrm{~km}$ with $q=0.9$. Disturbances generated by other high mountains are seen to the east of MB.

trapped lee waves. As in model 3, they exhibit decay and vertical phase lines above $7 \mathrm{~km}$.

Another interesting aspect of Fig. 10 is the weak train of periodic waves between altitudes of 9 to $11 \mathrm{~km}$ with wavelength of $25 \mathrm{~km}$. Waves with this downstream wavenumber (i.e., $k=0.00025 \mathrm{~m}^{-1}$ ) propagate nondispersively in layer 1 as $k \ll N_{1} / U_{1}$, but they disperse above $7 \mathrm{~km}$ after entering layer 2. Dispersive waves exhibit a more sinusoidal pattern. They cannot be trapped lee waves, as there is no resonant cavity in the model 4 run. Unfortunately, there were no aircraft legs or lidar cloud observations in this altitude range to test this prediction of the model.

In Figs. 11 and 12, the models 3 and 4 planview patterns of vertical displacement at $7.5 \mathrm{~km}$ are seen. This is the level of the C-130 legs. One is immediately struck by the three-dimensional complexity of the wave fields. East of MB, added complexity comes from waves produced by the Monte Rosa terrain. The Monte Rosa waves influence the northeast end of the Mont Blanc flight track. In Fig. 11 (model 3) the track goes through a field of periodic lee waves from Monte Rosa. In Fig. 12 (model 4) this lee-wave train is missing.

A more quantitative comparison of model and observation is shown in Fig. 13. In this figure, vertical velocity and potential temperature measured on the C130 are compared with vertical velocity and displace- ment predicted from models 3 and 4 . The model values are picked out of the computed 3D wave fields at the actual position of the aircraft during each pass. Thus, each traverse gives slightly different values, as well as slightly different terrain below the aircraft. To compare potential temperature with displacement, a generic value of static stability $\left(d \Theta / d z=3^{\circ} \mathrm{C} \mathrm{km}^{-1}\right)$ has been used.

In general, the agreement between model 4 and the observed vertical velocity is good, but the predicted amplitude is slightly too high. The wave amplitude is sensitive to the choice of $Z_{\text {ref }}$, however. A slightly higher $Z_{\text {ref }}$ would reduce the effective mountain height and reduce the wave to the observed amplitude level. The predicted potential temperature amplitude is also too high, but this may be partly because of our arbitrary choice of local stability used for plotting. In both model and observations, the oscillations in vertical velocity lead the potential temperature oscillations by a quarter cycle, as they should do in standing mountain waves.

It is clear from Fig. 13 that the waves predicted by linear theory are shifted slightly upstream with respect to the observations. The amount of this shift is about 3 $\mathrm{km}$. A related problem is the cutting of the leeside terrain by the lowest streamlines seen in Figs. 9 and 10. Both problems would be solved if the wave field were shifted downstream a slight amount. This error is due to the linear theory practice of applying the lower boundary 


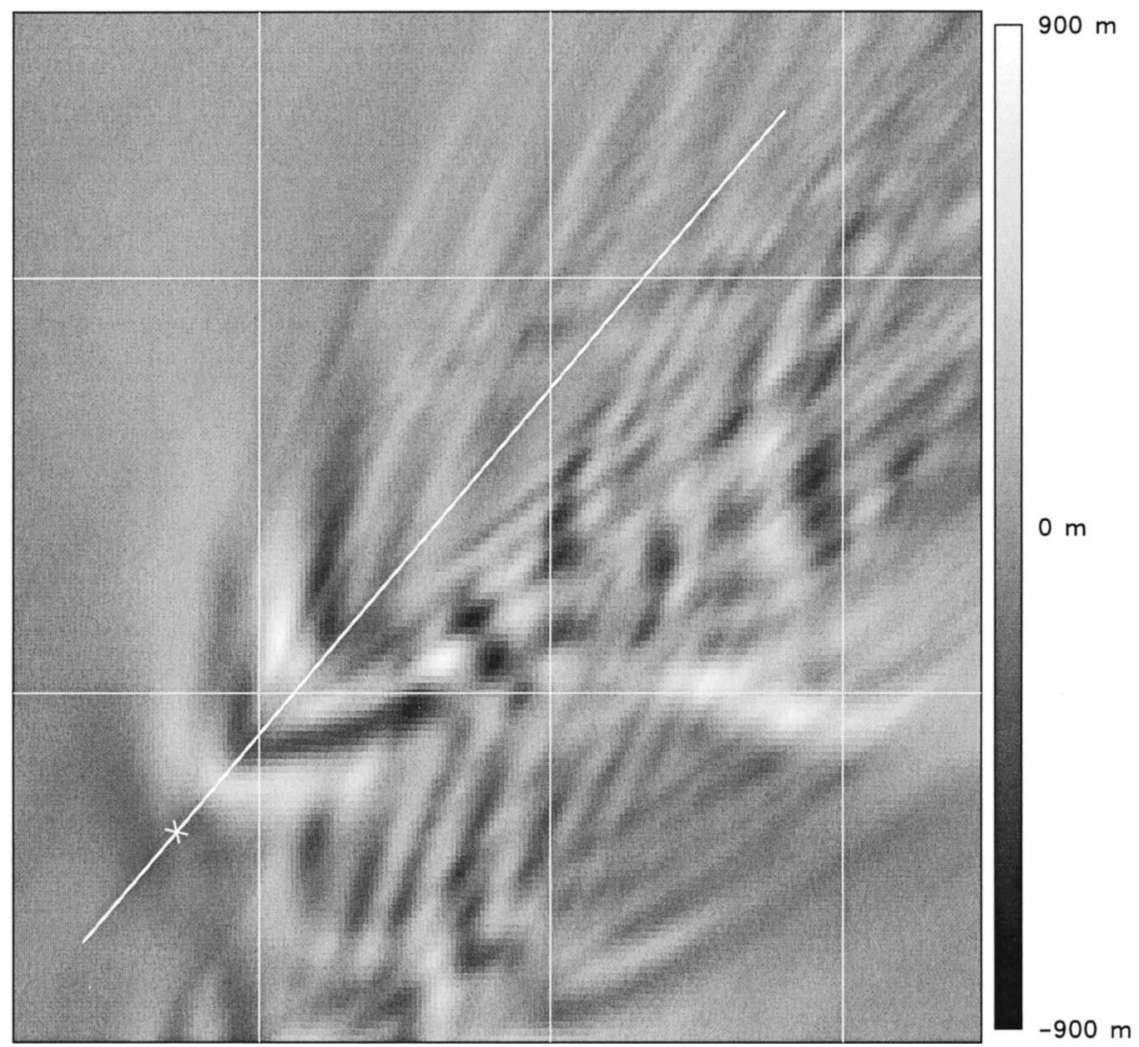

FIG. 12. Similar to Fig. 11, but with the reflection coefficient $q=0.0$. Note differences in the lee-wave field along the flight track.

condition (7) at the reference level, instead of on the mountain surface. At the mountain top, the computed wave field has already shifted upstream due the upstream tilt of vertically propagating waves. According to Smith (1988) the leeside streamline cutting is a particular problem in isolated terrain as the finite lateral wavenumber increases the vertical wavenumber (4) and the phase tilt. The fully nonlinear terrain-following COAMPS solution did not exhibit the phase shift problem (Fig. 13).

To compare the model with the Meteosat images, we computed the vertical displacement from Model 4 at $z$ $=14 \mathrm{~km}$ (Fig. 14). Models 3 and 4 are qualitatively similar at this altitude, but they differ quantitatively due to the leakage of trapped waves. Only upward-propagating waves are present. The pattern at $z=14 \mathrm{~km}$ is complex, but understandable. The forward part of the disturbance is in the form a downstream-trailing parabola, similar to that predicted by hydrostatic theory (Smith 1980), given by

$$
x=(U / N a z) y^{2} .
$$

The coefficient in brackets in (11) can be estimated using average values of $U=20 \mathrm{~m} \mathrm{~s}^{-1}, N=0.01 \mathrm{~s}^{-1}$, $a=4000 \mathrm{~m}$, and $z=12000 \mathrm{~m}$, to give $0.00005 \mathrm{~m}^{-1}$. The disturbances seen downstream of the first parabola are nonhydrostatic dispersive waves.
The time needed for hydrostatic waves to reach this altitude can be estimated from the vertical component of the group velocity

$$
C_{g}=U^{2} k^{2} / N\left(k^{2}+l^{2}\right)^{1 / 2} .
$$

For normal waves with $l=0$, and with $U=20 \mathrm{~m} \mathrm{~s}^{-1}$, $N=0.01 \mathrm{~s}^{-1}$, and $k^{-1}=a=4000 \mathrm{~m}$, (12) gives $C_{g}$ $=10 \mathrm{~m} \mathrm{~s}^{-1}$ and so the time required to build a $14-\mathrm{km}^{-}$ deep wave field is only $1400 \mathrm{~s}$ or $23 \mathrm{~min}$. Thus, it is not surprising that at least some spectral components of the wave field can maintain a nearly steady-state structure at an altitude of $14 \mathrm{~km}$.

The magnitude of the momentum flux (MF) associated with the vertically propagating waves is extremely sensitive to the value of $Z_{\text {ref }}$ (Table 2). As $Z_{\text {ref }}$ is lowered, the height of the effective mountains increases, as does their width and number. With $q=0.9$, MF is approximately proportional to the mountain volume above $Z_{\text {ref }}$, and it can be represented as $\mathrm{MF}=\left(C \rho_{0} U_{1} N_{1}\right)$ volume, where $C=0.016$. The use of this formula requires an estimate of $Z_{\text {ref }}$ or the exposed mountain volume. Setting the reflection coefficient equal to zero reduces the momentum flux considerably. Trapped waves that would otherwise leak upward, contributing to MF, are absorbed at the lower boundary before they can do so. Those portions of the wave spectrum that are reflected downward from the jet stream and then absorbed, carry a 


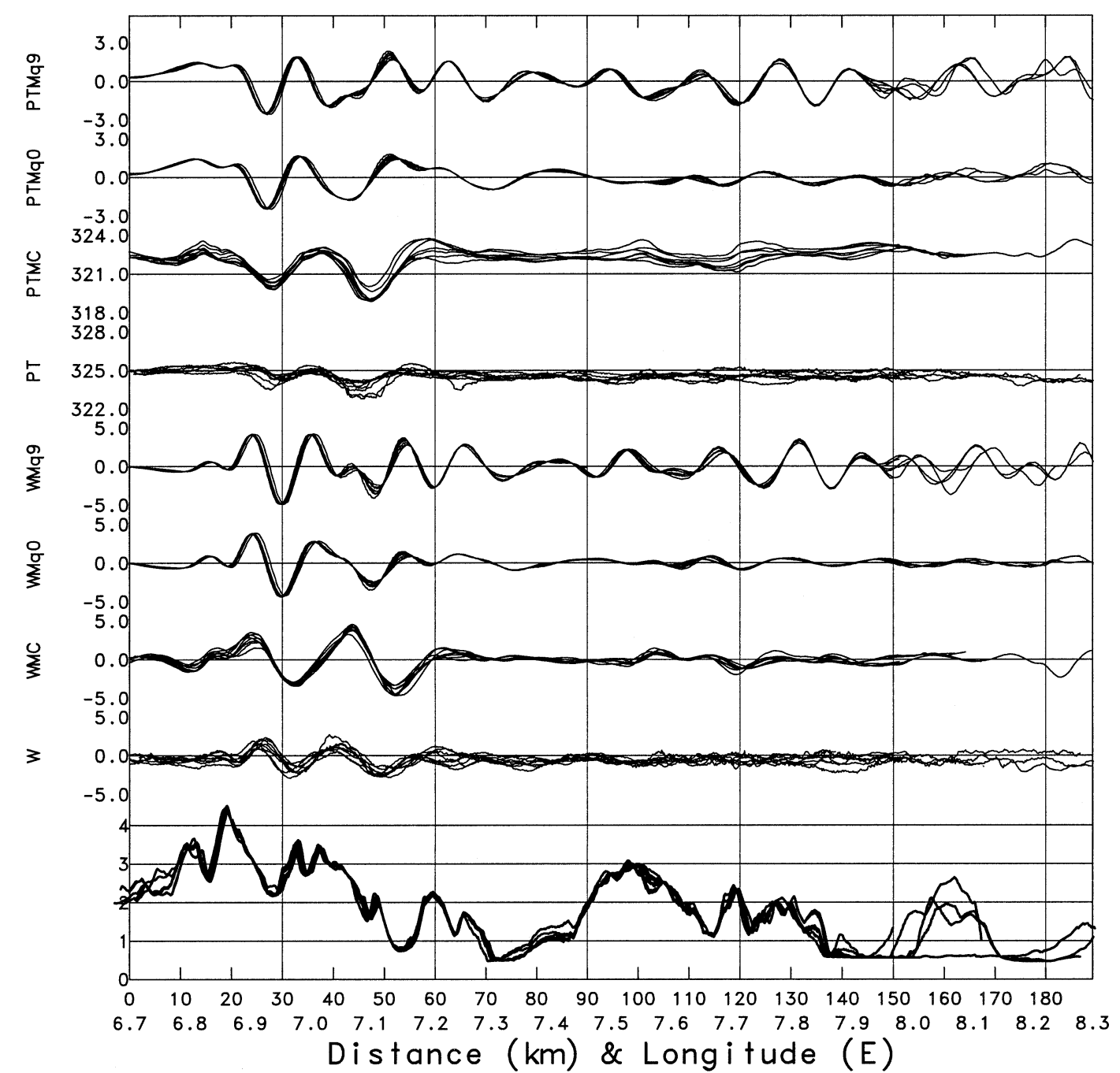

FIG. 13. Comparison of potential temperature (top four curves) and vertical velocity values (next four curves) from three models, linear theory with $q=0.9$ and $q=0.0$ and the COAMPS integration, and observed by the C-130. Data are picked out from the model fields at the actual position of the aircraft for each repeated leg. Terrain under the aircraft is shown at the bottom of the figure.

negative momentum flux downward from the exposed mountain to the stagnant boundary layer.

\section{Nonlinear aspects of the dynamics}

The comparison of linear theory with observations in the previous section has identified two possible nonlinear aspects of the flow: 1) formation of the stagnant layer in the low troposphere, and 2) absorption of downward reflected waves. We will investigate these aspects with a numerical model. We are also interested in the general ability of mesoscale forecast models to predict gravity waves and breaking using large-scale initialization and boundary conditions.

The nonlinear numerical simulations of idealized and observed flows for this study were prepared with the atmospheric portion of the Naval Research Laboratory's
COAMPS (Hodur 1997; Hodur and Doyle 1999). The COAMPS model has been used in previous studies of flow over mountains (Doyle and Shapiro 1999; Doyle et al. 2000).

The domain configuration for the real data simulations contains four horizontally nested grid meshes of $85 \times 85,97 \times 97,133 \times 133$, and $235 \times 235$ points, respectively. The horizontal grid increments of the computational meshes are $27,9,3$, and $1 \mathrm{~km}$, respectively. The model top is at $22 \mathrm{~km}$ with 55 vertical levels. The vertical grid increment is $10 \mathrm{~m}$ at the lowest level, and stretched to $500 \mathrm{~m}$ above $7 \mathrm{~km}$. An incremental update data assimilation procedure that enables mesoscale phenomena to be retained in the analysis increment fields is used to initialize the real data simulations. The initial fields for the model are created from multivariate optimum interpolation analyses of upper-air sounding, sur- 


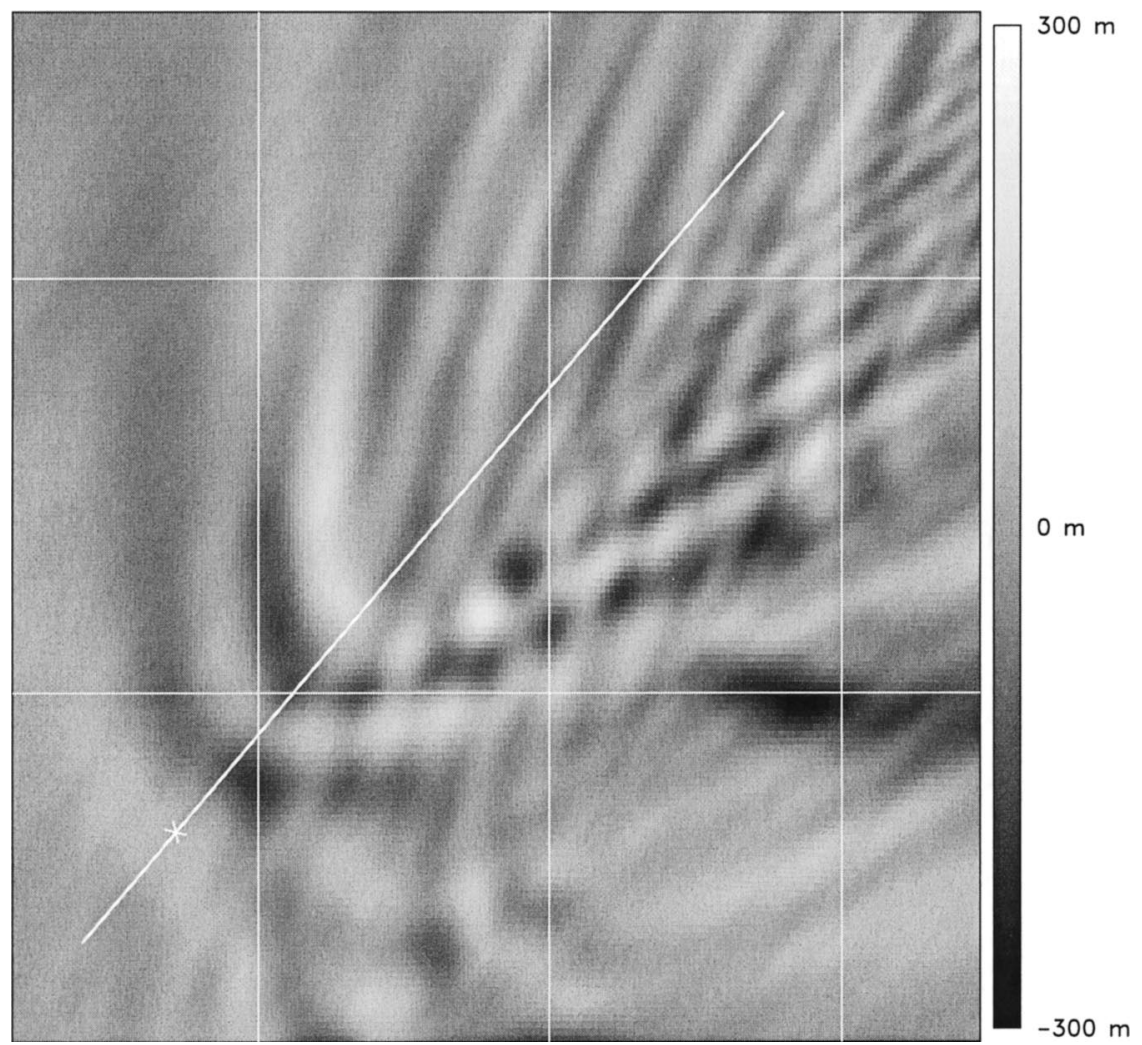

FIG. 14. The linear theory field of vertical displacement at upper levels $(z=14 \mathrm{~km})$ with $q$ $=0.0$. These data are from the same computation shown in Figs. 10 and 12. The wave field at this altitude is composed entirely of vertically propagating waves.

face, aircraft, and satellite data that are quality controlled and blended with the 12-h COAMPS forecast fields. Real data lateral boundary conditions make use of the U.S. Navy Operational Global Analysis and Prediction System (NOGAPS). The topographic data for the real data simulations are based on the U.S. Defense Mapping Agency's 100-m resolution dataset.

A series of simplified idealized numerical simulations based upon synthetic initial conditions were performed to isolate the response to the flow impinging upon Mont Blanc. The domain configuration for these idealized initial condition numerical experiments used a single grid with $201 \times 201$ points and a horizontal grid increment of $1 \mathrm{~km}$. The model top is at $20 \mathrm{~km}$ with 80 irregularly spaced vertical levels. A Gaussian-shaped mountain is used to represent the topography. The lateral boundary condition formulation is based on a radiation condition with a prescribed group velocity that is invariant in time. The idealized simulations are adiabatic, make use of a free-slip lower boundary condition, and are performed without rotation.

\section{a. The stagnant layer}

Several real data simulations were conducted using varying domain sizes and data assimilation methodol- ogies. For the most part, these runs tended to have too strong a flow at low levels, generating a too-strong wave field. The most realistic simulation made use of the largest inner-mesh domain and featured the most pronounced low-level blocking. The wave field from this COAMPS simulation is shown in Fig. 15. The corresponding flight level data for the C-130 is shown in Fig. 13. In Fig. 13, the location of the two wave crests agrees with observations, but the amplitude is too large. In Fig. 15 , little phase tilt is seen in the upper troposphere, and no lee waves are seen. The stagnant layer is playing a dual role, reducing the wave generation and absorbing downward-reflected waves. The low-level blocking is regional rather than local, as shown in Fig. 16. While strong flow below $2500 \mathrm{~m}$ persists to the northwest of Mont Blanc, the flow upstream and to the southeast is weak. The blocking is not caused by MB alone, but by the full complex terrain of the northwestern Alps.

A persistent problem with the COAMPS real data simulation was the flow direction. The observed largescale mean flow had a direction of $220^{\circ}$ and was oriented nearly parallel to the ridgeline of the MB massif. The real data simulation in this case contained an upstream mean wind direction of $\sim 230^{\circ}-235^{\circ}$, which resulted in a displacement of the vertical velocity extrema associated with the Mont Blanc lee wave outside of the two- 


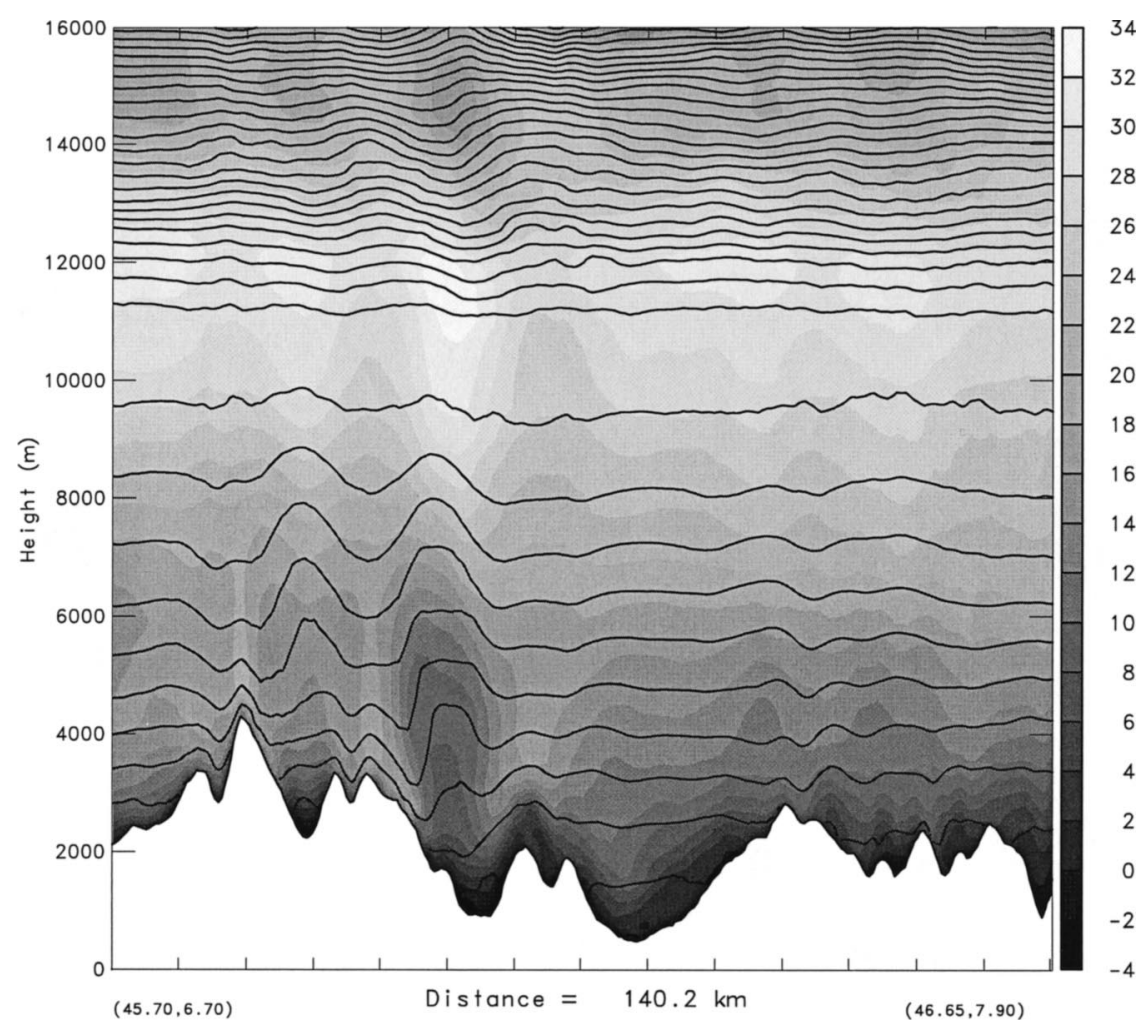

FIG. 15. The vertical displacements of potential temperature surfaces and horizontal wind speed predicted by the nested real data COAMPS run. The section is similar to Figs. 9 and 10, but from the COAMPS model. Two displacement crests are seen with little phase shift in the upper troposphere and no periodic lee waves. Note the low-level stagnant layer distorted by the wave field. In the stratosphere, small amplitude waves are seen.

dimensional plane defined by the aircraft flight leg. The prediction of regional wind direction is particularly critical because the resulting gravity wave structures from complex terrain are highly three-dimensional.

\section{b. Absorption of downward reflected waves}

In section 7 we developed the hypothesis that a lowlevel stagnant layer induced by surrounding complex terrain will weaken wave generation and absorb downgoing waves. To evaluate this hypothesis, we performed two idealized COAMPS and two idealized linear runs with the three-layer temperature and wind speed sounding in Table 1. The wind direction is modified to be westerly. The sounding is smoothed in the COAMPS run to prevent shear instability at the layer interfaces.

TABLE 2. Mont Blanc regional momentum flux from the linear model.

\begin{tabular}{cccc}
\hline \hline & $\begin{array}{c}\text { Volume } \\
Z_{\text {ref }}(\mathrm{m})\end{array}$ & MF $\left(10^{8} \mathrm{~N}\right) ;$ & MF $\left(10^{8} \mathrm{~N}\right) ;$ \\
\hline 1500 & 6481 & $2=0.9$ & $q=0$ \\
2500 & 988 & 24.4 & 133 \\
3500 & 25 & 0.58 & 16.7 \\
& & & 0.28 \\
\hline
\end{tabular}

In the first COAMPS run, the flow passes along a rigid lower boundary and over a 1000-m Gaussian hill. The hill shape is the top $1000 \mathrm{~m}$ of a $1500-\mathrm{m}$ Gaussian shape with an $e$-folding width of $5 \mathrm{~km}$. The vertical parcel displacements at a level $1000 \mathrm{~m}$ above the mountain top are shown in Fig. 17a. A well-developed set of trapped diverging lee waves is seen. The same hill shape and wind/stability profile is used in the linear theory solution shown in Fig. 17b. The reflection coefficient is set to a large value $(q=0.9)$. The linear solution is nearly identical to the COAMPS solution.

In the second COAMPS run, a 500-m-deep stagnant layer was prescribed above the lower boundary, with a 1500-m Gaussian mountain, so that the mountain penetrates $1000 \mathrm{~m}$ into the moving airstream. The mountain shape exposed to the airstream is the same as in the runs described above. The vertical parcel displacements at a level $1000 \mathrm{~m}$ above the mountain top are shown in Fig. 17c. In this run, lee waves are absent. Only dispersing vertically propagating waves appear. The top of the stagnant layer (not shown) is strongly disturbed as one would expect if critical layer wave absorption is occurring (Booker and Bretherton 1967).

Stagnant low-level conditions are modeled with linear theory by setting the reflection coefficient to $q=0.0$. 


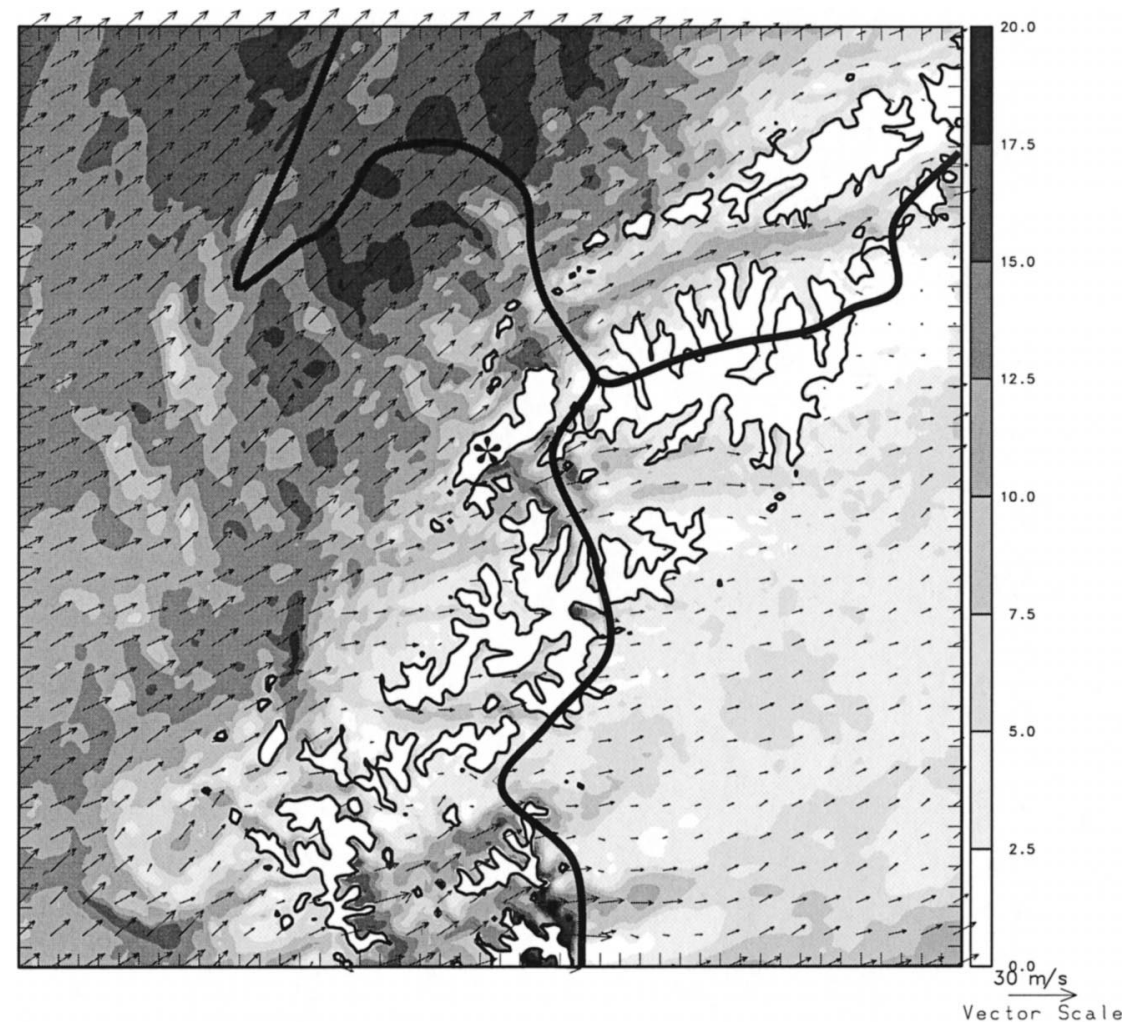

FIG. 16. The wind speed at $z=2500 \mathrm{~m}$ is shown for the same COAMPS run and time as in Fig. 15. Wind vectors and speed (shaded) are shown. The 2500-m topographic contour is also shown. Strong winds exist northwest of MB, but elsewhere, only weak winds are found. The position of MB is indicated with an asterisk.

The same 1000-m truncated Gaussian mountain and three-layer atmospheric structure is used. The displacement field at an altitude of $1 \mathrm{~km}$ above the mountain top is shown in Fig. 17d. No lee waves are seen, as in Fig. 17c. The agreement between the linear and COAMPS model is remarkably good, confirming the use of the $q=0$ condition in the linear model to capture the effect of absorption of down-going waves by a stagnant layer. The excellent agreement between Figs. 17a and $17 \mathrm{~b}$ also builds confidence in the ability of both models to handle the subtle dynamics of three-dimensional trapped lee waves. Note that the basic state supports only diverging lee waves, not the better-known transverse lee waves (Sawyer 1962; Gjevik and Marthinsen 1978). Nevertheless, the difference between the flows with reflecting and absorbing lower boundary conditions is striking.

The ability of linear theory to handle such a large mountain (i.e., $1 \mathrm{~km}$ ) is due to the moderately strong low-level wind speed $\left(15 \mathrm{~m} \mathrm{~s}^{-1}\right)$, the isolated nature of the hill, and the lack of strong vertical structure in the temperature profile, such as an inversion. The vertical displacement of an inversion can promote nonlinearity (Smith 1976, 1989).

\section{Conclusions}

The new observing technologies tested in this project provided substantial new information about mountain wave structure during the 2 November Mont Blanc event. Multiple dropsondes gave an improved estimate of the mean wind and stability profile through which the waves must propagate. The identification of the lowlevel stagnant layer was critical to our analysis. Airborne lidar provided repeated snapshots of how the waves disturb the cloud field. It provided independent estimates of wave amplitude, phase, and steadiness at several altitudes and gave evidence of plunging flow over the mountain peak. The latter observation strongly indicated that Mont Blanc was the source of the wave disturbance. The effectiveness of the lidar depended on a fortunate vertical distribution of cloud layers that provided backscatter energy. Rapid scan satellite images allowed stationary and drifting disturbances to be identified at cloud top. These new methods, however, would be of little quantitative use without the repeated aircraft measurements of vertical air motion and temperature using conventional airborne instruments. The strategy of repeating flight legs was essential in testing the steady-state hypothesis. 

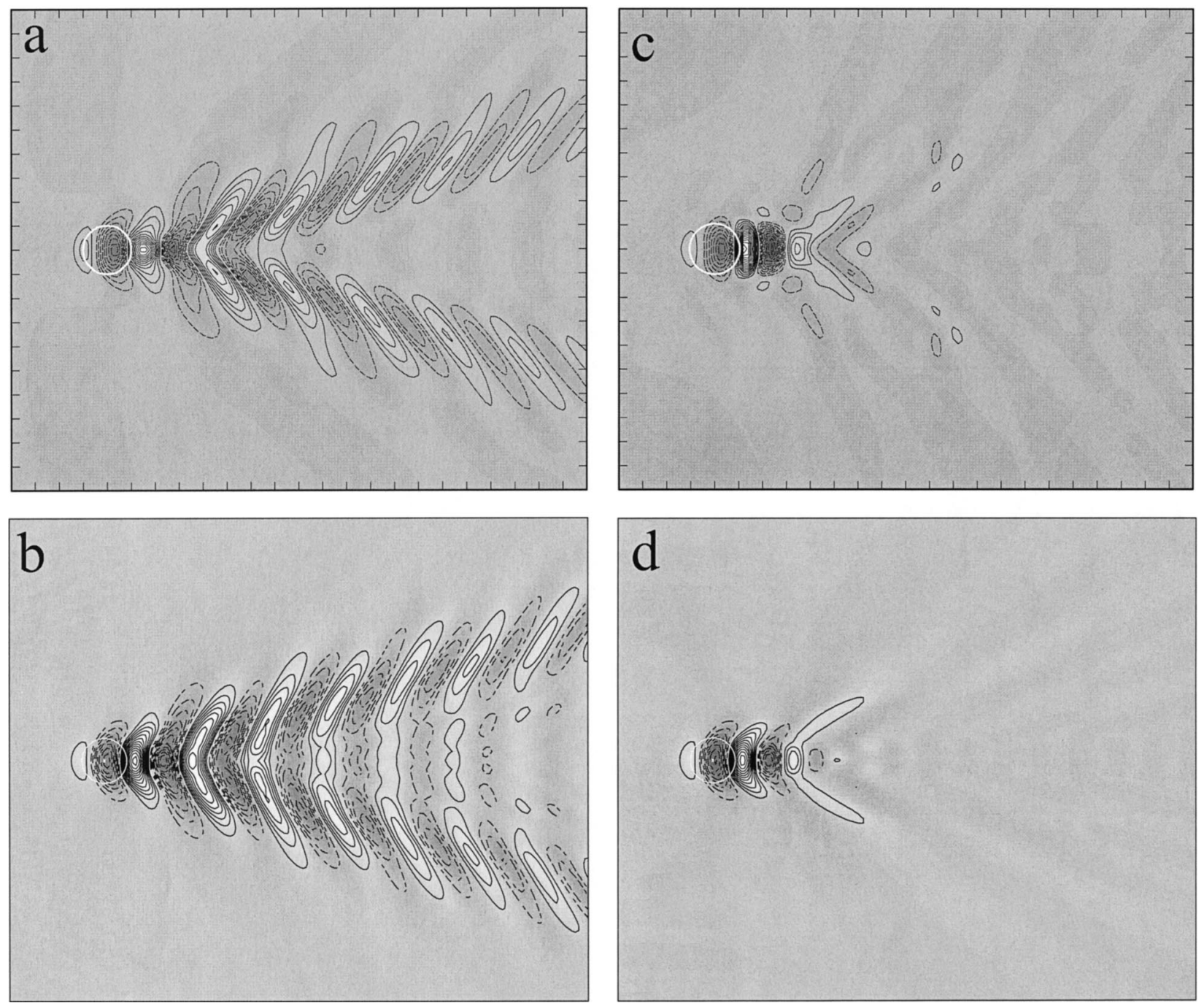

FIG. 17. Idealized runs to test the hypothesis that a low-level stagnant layer will absorb down-going waves and prevent lee-wave formation. Calculations were done with a 1000-m truncated Gaussian hill so that the hill exposed to the flow is the same in all cases. The mean flow is westerly with a wind speed and temperature profile given by the idealized reference sounding (Table 1). Vertical velocity is shown with a contour interval of $0.5 \mathrm{~m} \mathrm{~s}^{-1}$. (a) COAMPS run without a 500-m stagnant layer. (b) Linear theory solution with a reflective lower boundary $(q=0.9)$. (c) COAMPS run with a 500-m stagnant layer. (d) Linear theory solution with an absorbing lower boundary $(q=0.0)$. Diverging lee waves are seen in (a) and (b), but not (c) and (d), due to absorption of down-going waves.

The observed wave field is rather well predicted by a three-layer three-dimensional linear theory model, using the observed mean wind and stability profiles. Nonlinear effects have a minor influence in this case in the middle and upper troposphere. Two free parameters are included in the linear model: a reference height and a reflection coefficient at the lower boundary. The reference height is constrained to lie between 2500 and $3200 \mathrm{~m}$ by dropsonde measurements of the low-level stagnant layer. Two values of reflection coefficient $(q$ $=0.9$ and 0.0 ) are tested against our data.

The mean wind and temperature conditions near Mont Blanc on 2 November had several characteristics that played a role in wave generation, propagation, and dissipation. The stagnant layer below $2500 \mathrm{~m}$ reduced the generation of mountain waves and absorbed reflected down-going waves. The upper tropospheric layer of moderate winds and low stability (i.e., low Scorer parameter) made the shorter wave components evanescent there, giving decay and vertical phase lines. The lack of wind turning eliminated the possibility of critical layer absorption.

The evidence for evanescent wave behavior in the upper troposphere and the lack of observed trapped lee waves represent a paradox. Existing lee-wave theory links evanescence and trapping. To resolve this paradox, we hypothesize that the waves reflected downward by the jet stream are being absorbed at the top of the stagnant layer. Setting the reflection coefficient $q=0$ in linear theory improves the agreement with data sub- 
stantially. Idealized model runs with a nonlinear model confirmed this hypothesis.

The broader implication of this result is that lee-wave absorption at the lower boundary might be a frequent cause of lee-wave decay, in addition to the accepted mechanism of leakage aloft. With a typical atmospheric boundary layer over smooth terrain or water, this absorption may be relatively small. Under such circumstances, periodic lee-wave clouds and ocean surface roughness patterns have been seen in satellite images to extend for $200 \mathrm{~km}$ downstream of mountain ridges. Over complex terrain such as the Alps, stagnant lowlevel air may partially or totally absorb downward reflected waves. A reduction in wave momentum flux may result. We have not examined the detailed mechanism of wave absorption, or how it depends on the depth of the stagnant layer. Existing work on how the boundary layer influences mountain waves may provide some insight (Richard et al. 1989).

The lidar and Meteosat data illustrate different ways that waves can modify the cloud field over mountains. Mountain waves can vertically displace existing cloud layers as well as create lenticular clouds. Fall streaks can be distorted by waves.

Our experience with real-time and postproject simulation suggests that reliable detailed forecasting of a wave field and wave breaking is not yet possible, in spite of recent advances in modeling. Adjustment of the linear model using the observed wind profile was necessary to get good agreement with the wave field. The values of reflection coefficient $q$ and base level $Z_{\text {ref }}$ are powerful tuning parameters. In COAMPS, model resolution and/or domain size can influence the degree of low-level stagnation and other aspects of the mean field. Gravity wave generation and the reflection of downgoing waves are quite sensitive to the low-level wind speed and direction. Vertical wave propagation and/or evanescence are sensitive to wind and stability in the upper troposphere.

Acknowledgments. MAP scientists, forecasters, staff, ATC, and flight crews were essential in the pursuit of this research. Other members of the gravity wave breaking team-Dave Fritts, Greg Poulos, Samantha Smith, Joachim Kuettner, and K. P. Hoinka-aided in the track planning and execution. The Yale group was supported by the ATM division of the National Science Foundation (Grant 9711076). The Falcon flight hours were supported jointly by NSF and DLR. The C-130 was supported by the Met Office. The Electra was supported by the NSF and operated by the Research Aviation Facility at the National Center for Atmospheric Research. Support for MAP from several European weather services is gratefully acknowledged. Appendix B was provided by Gerhard Ehret. Meteosat data was provided by Eumetsat.

\section{APPENDIX A}

\section{Linear Model Coefficients}

The up- and down-going wave amplitude coefficients of the three-layer model $A_{i}(k, l)$ and $B_{i}(k, l)$ are computed from the transform of the terrain $\hat{h}(k, l)$ using the parameters that define each layer $\left(m_{i}, \sigma_{i}, z_{i}\right)$. The expressions are

$$
\begin{array}{ll}
A_{3}=h /(F A E+q \cdot F B E), & A_{1}=F A E \cdot A_{3}, \\
B_{1}=F B E \cdot A_{3}, & A_{2}=F C E \cdot A_{3}, \\
B_{2}=F D E \cdot A_{3}, &
\end{array}
$$

where

$$
\begin{aligned}
F C E= & (1 / 2)\left[1+R_{32}\right] \exp \left(i m_{3} z_{2}-i m_{2} z_{2}\right), \\
F D E= & (1 / 2)\left[1+R_{32}\right] \exp \left(i m_{3} z_{2}-i m_{2} z_{2}\right), \\
F A E= & (1 / 4)\left[\left(1+R_{21}\right)\left(1+R_{32}\right)\right] \\
& \times \exp \left[i\left(m_{2}-m_{1}\right) z_{1}+i\left(m_{3}-m_{2}\right) z_{2}\right] \\
& +(1 / 4)\left[\left(1-R_{21}\right)\left(1-R_{32}\right)\right. \\
& \times \exp \left[-i\left(m_{2}+m_{1}\right) z_{1}+i\left(m_{3}+m_{2}\right) z_{2}\right], \\
F B E= & (1 / 4)\left[\left(1-R_{21}\right)\left(1+R_{32}\right)\right] \\
& \times \exp \left[i\left(m_{2}+m_{1}\right) z_{1}+i\left(m_{3}-m_{2}\right) z_{2}\right] \\
& +(1 / 4)\left[\left(1+R_{21}\right)\left(1-R_{32}\right)\right] \\
& \times \exp \left[-i\left(m_{2}-m_{1}\right) z_{1}+i\left(m_{3}+m_{2}\right) z_{2}\right],
\end{aligned}
$$

where

$$
R_{32}=m_{3} \sigma_{3}^{2} / m_{2} \sigma_{2}^{2}, \quad R_{21}=m_{2} \sigma_{2}^{2} / m_{1} \sigma_{1}^{2} .
$$

All these quantities are complex. Note that when the atmospheric conditions are uniform with height, $R_{21}=$ $R_{32}=1$ and the down-going wave amplitudes $B_{1}=B_{2}$ $=0$.

\section{APPENDIX B}

\section{DLR's Airborne DIAL System}

A new DLR airborne DIAL system provides simultaneous measurements of atmospheric backscatter and water vapor concentration. It contains two transmitters based on all-solid-state laser technology. This enables high peak and average output power needed for highresolution measurements, as well as a compact design and low power consumption $(\sim 2 \mathrm{~kW})$. A unique feature of the system is also its capability to operate in the spectral region around $940 \mathrm{~nm}$, which is required for measurements of very low water vapor contents in the upper troposphere and lower stratosphere. The fundamental output wavelength at $1064 \mathrm{~nm}$, which is used for atmospheric backscatter measurements, is provided by a diode-pumped Q-switched injection-seeded $\mathrm{Nd}$ : 
YAG laser (Rofin-Sinar GmbH) (Ehret et al. 2000). This laser operates at $100-\mathrm{Hz}$ repetition rate and delivers 15 ns-long pulses with an energy of over $200 \mathrm{~mJ}$. Approximately one-half of the output power is used for high-resolution backscatter measurements. The rest is converted to the second harmonic at $532 \mathrm{~nm}$, which further serves as a pump for the $\mathrm{H}_{2} \mathrm{O}$ DIAL transmitter based on an injection-seeded potassium titanyl phosphate-optical parametric oscillator (KTP-OPO).

The system aboard the Falcon can be positioned to look either downward or upward. The backscattered light is collected with a 35-cm Cassegrainian-type telescope with a focal length of $500 \mathrm{~cm}$ and an adjustable field-of-view, typically set to $1 \mathrm{mrad}$. The received light is split into two channels, for atmospheric backscatter and water vapor measurements, and detected by means of APDs. In order to suppress the solar background light at daytime, filters with 1-nm FWHM and 70\% peak transmission are used. The individual signals are digitized with a resolution of 14 bit at a sampling rate of $10 \mathrm{MHz}$. The data can be averaged by different factors and are stored on the hard disk, magnetic tape, and removable magneto optic disk.

\section{REFERENCES}

Booker, J. R., and F. P. Bretherton, 1967: Critical layer for internal gravity waves in a shear flow. J. Fluid Mech., 27, 513-539.

Bougeault, P., and Coauthors, 2001: The MAP special observing period. Bull. Amer. Meteor. Soc., 82, 433-462.

Broad, A. S., 1995: Linear theory of momentum fluxes in 3-D flows with turning of the mean wind with height. Quart. J. Roy. Meteor. Soc., 121, 1891-1902.

Chen, W. D., and R. B. Smith, 1987: Blocking and deflection of airflow by the Alps. Mon. Wea. Rev., 115, 2578-2597.

Doyle, J. D., and M. A. Shapiro, 1999: Flow response to large-scale topography: The Greenland tip jet. Tellus, 51A, 728-748.

— , and Coauthors, 2000: An intercomparison of model-predicted wave breaking for the 11 January 1972 Boulder windstorm. Mon. Wea. Rev., 128, 901-914.

Ehret, G., and Coauthors, 2000: High peak and average power all- solid-state laser systems for airborne lidar applications. Laser Opto., 32, 29-37.

Gjevik, B., and T. Marthinsen, 1978: Three-dimensional lee-wave pattern. Quart. J. Roy. Meteor. Soc., 104, 947-957.

Heimann, D., 1997: Mesoscale surface-wind characteristics and potential gravity-wave formation during cross-Alpine airflow. Meteor. Atmos. Phys., 62, 49-70.

Hodur, R. M., 1997: The Naval Research Laboratory's Coupled Ocean/Atmosphere Mesoscale Prediction System (COAMPS). Mon. Wea. Rev., 125, 1414-1430.

— scale model prediction system (COAMPS). Coastal Ocean Prediction, C. N. K. Mooers, Ed., Coastal and Estuarine Studies, Vol. 56, American Geophysical Union, 125-155.

Richard, E., P. Mascart, and E. C. Nickerson, 1989: Role of surface friction in downslope windstorms. J. Appl. Meteor., 28, 241251.

Sawyer, J. S., 1962: Gravity waves in the atmosphere as a threedimensional problem. Quart. J. Roy. Meteor. Soc., 88, 412-427.

Scorer, R. S., 1949: Theory of waves in the lee of mountains. Quart. J. Roy. Meteor. Soc., 75, 41-56.

Sharman, R. D., and M. G. Wurtele, 1983: Ship waves and lee waves. J. Atmos. Sci., 40, 396-427.

Shutts, G. J., and A. Gadian, 1999: Numerical simulations of orographic gravity waves in flows which back with height. Quart. J. Roy. Meteor. Soc., 125, 2743-2765.

Simard, A., and W. R. Peltier, 1982: Ship waves in the lee of isolated topography. J. Atmos. Sci., 39, 587-609.

Smith, R. B., 1976: Generation of lee waves by blue ridge. J. Atmos. Sci., 33, 507-519.

— 1980: Linear theory of stratified hydrostatic flow past an isolated mountain. Tellus, 32, 348-364.

_ 1988: Linear theory of stratified flow past an isolated mountain in isosteric coordinates. J. Atmos. Sci., 45, 3889-3896.

_, 1989: Hydrostatic air-flow over mountains. Advances in Geophysics, Vol. 31, Academic Press, 1-41.

, 2001: Stratified flow over topography. Environmental Stratified Flows, R. Grimshaw, Ed., Kluwer, 121-159.

Steinacker, R., 1982: Synoptische feinanalysen auf isentropenflachen im alpenraum. Ann. Meteor., 19, Deutscher Wetterdienst, Offenbach, 34-36.

Thorpe, A. J., H. Volkert, and D. Heimann, 1993: Potential vorticity of flow along the Alps. J. Atmos. Sci., 50, 1573-1590.

Vosper, S. B., and S. D. Mobbs, 1996: Lee waves over the English Lake District. Quart. J. Roy. Meteor. Soc., 122, 1283-1305.

Welch, W., P. Smolarkiewicz, R. Rotunno, and B. A. Boville, 2001: The large-scale effects of flow over periodic mesoscale topography. J. Atmos. Sci., 58, 1477-1492. 